\title{
Epilepsy-induced abnormal striatal plasticity in Bassoon mutant mice
}

\author{
Veronica Ghiglieri, ${ }^{1, \star}$ Barbara Picconi, ${ }^{1, \star}$ Carmelo Sgobio,,${ }^{1}$ Vincenza Bagetta, ${ }^{1}$ Ilaria Barone,${ }^{1}$ Vincent Paillè, ${ }^{1}$ \\ Massimiliano Di Filippo, ${ }^{1,2}$ Federica Polli, ${ }^{3}$ Fabrizio Gardoni, ${ }^{3}$ Wilko Altrock, ${ }^{4}$ Eckart D. Gundelfinger, ${ }^{4}$ \\ Giovambattista De Sarro, ${ }^{5}$ Giorgio Bernardi, ${ }^{1}$ Martine Ammassari-Teule, ${ }^{6}$ Monica Di Luca ${ }^{3}$ and Paolo Calabresi ${ }^{1,2}$ \\ ${ }^{1}$ Laboratorio di Neurofisiologia, Fondazione Santa Lucia, IRCCS c/o CERC, Rome, Italy \\ ${ }^{2}$ Clinica Neurologica, Dip. Specialità Medico Chirurgiche e Sanità Pubblica, Università di Perugia, Italy \\ ${ }^{3}$ Center of Excellence on Neurodegenerative Diseases and Department of Pharmacological Sciences, University of Milan, Milan, \\ Italy \\ ${ }^{4}$ Leibniz Institute for Neurobiology, Magdeburg, Germany \\ ${ }^{5}$ Facoltà di Medicina e Chirurgia, Università degli Studi Magna Graecia di Catanzaro, Campus di Germaneto, Italy \\ ${ }^{6}$ Istituto di Neuroscienze del CNR, Sezione di Psicobiologia e Psicofarmacologia, Fondazione Santa Lucia, IRCCS, Rome, Italy
}

Keywords: dorsolateral striatum, fast-spiking interneurons, postsynaptic density, scaffolding proteins, synaptic plasticity

\begin{abstract}
Recently, the striatum has been implicated in the spread of epileptic seizures. As the absence of functional scaffolding protein Bassoon in mutant mice is associated with the development of pronounced spontaneous seizures, we utilized this new genetic model of epilepsy to investigate seizure-induced changes in striatal synaptic plasticity. Mutant mice showed reduced long-term potentiation in striatal spiny neurons, associated with an altered $\mathrm{N}$-methyl-D-aspartate (NMDA) receptor subunit distribution, whereas GABAergic fast-spiking (FS) interneurons showed NMDA-dependent short-term potentiation that was absent in wild-type animals. Alterations in the dendritic morphology of spiny neurons and in the number of FS interneurons were also observed. Early antiepileptic treatment with valproic acid reduced epileptic attacks and mortality, rescuing physiological striatal synaptic plasticity and NMDA receptor subunit composition. However, morphological alterations were not affected by antiepileptic treatment. Our results indicate that, in Bsn mutant mice, initial morphological alterations seem to reflect a more direct effect of the abnormal genotype, whereas plasticity changes are likely to be caused by the occurrence of repeated cortical seizures.
\end{abstract}

\section{Introduction}

Bassoon is an integral component of the presynaptic cytoskeleton that functionally interacts with other proteins to organize the highly specialized cytomatrix at active zones of regulated neurotransmitter release (tom Dieck et al., 1998; Winter et al., 1999). This regulatory activity can be exerted at both inhibitory and excitatory glutamatergic synapses and in several brain areas, including the cortex, hippocampus, and striatum (Richter et al., 1999; Garner et al., 2000; Schoch \& Gundelfinger, 2006). Mice lacking the central domain of the Bassoon gene $(B s n)$ display alterations in neuronal activity associated with the occurrence of spontaneous cortical seizures, which often lead to death in homozygous mutants (Altrock et al., 2003). These features make this mutant a novel genetic model of epilepsy and a useful tool to explore the role of specific brain circuits in the generation, propagation and recurrence of epileptic seizures. Although the involvement of cortical and hippocampal circuits in the genesis of epileptic activity

Correspondence: Dr Paolo Calabresi, ${ }^{2}$ Clinica Neurologica, as above.

E-mail calabre@unipg.it

*These authors contributed equally to this work.

Received 29 December 2008, revised 18 February 2009, accepted 28 February 2009 has been extensively characterized, the possible role of basal ganglia, and in particular of the striatum, in modulating seizures has only recently been postulated (Slaght et al., 2002; Bouilleret et al., 2008). Adaptive changes in striatal cell-type-specific synaptic plasticity might play a major role in the basal ganglia control of seizure activity. In fact, the striatum is the main input structure of the basal gangliathalamo-cortical loop, in which the functional interplay of converging excitatory and inhibitory inputs underlies the correct information processing needed to control motor learning and habit formation (Calabresi et al., 2007). This critical role of the striatum in basal ganglia relies on the interactions between medium spiny (MS) neurons and a subtype of GABAergic interneurons that express parvalbumin (PV), called fast-spiking (FS) interneurons on the basis of their electrophysiological characteristics (Kawaguchi, 1993). Striatal PVcontaining FS interneurons receive powerful excitatory input from the cortex and exert strong feedforward inhibition of MS neurons, their predominant synaptic target (Kawaguchi, 1993; Koos \& Tepper, 1999; Tepper et al., 2004; Mallet et al., 2005). Given the critical importance of FS interneurons in the balance of striatal MS neuron activity, which, in turn, shapes the activity of basal ganglia output nuclei, it is conceivable that the frequent spread of epileptic seizures 
throughout the cortex could profoundly alter both short-term and longterm excitability in the striatal neuronal subtypes as an adaptive mechanism.

Here, we tested the hypothesis that adaptive changes in the synaptic plasticity of striatal MS neurons and FS interneurons might occur. To this end, we characterized the corticostriatal pathway of Bsn mutant mice by in vitro intracellular recordings from striatal MS neurons and FS interneurons, and analysed possible correlations with molecular and morphological aspects. We also investigated the possibility that early, chronic treatment with the antiepileptic drug (AED) valproic acid (VPA) could influence the clinical expression of seizures as well as the molecular, electrophysiological and morphological abnormalities observed in this new genetic model of epilepsy.

\section{Materials and methods}

\section{Animals}

Mice lacking Bassoon (Bsn $\Delta \mathrm{Ex} 4 / 5)$ were generated as described previously (Altrock et al., 2003), back-crossed into the C57/bl6 mouse strain, and then crossed with the SV129 strain, yielding mice with a mixed C57/bl6-SV129 genetic background for mutants and wild types. Genotyping was performed by polymerase chain reaction, as described previously (Altrock et al., 2003); age-matched wild-type littermates were used as controls. At the beginning of the experiment, animals were $2-3$ months old, and their weights ranged from 23 to $28 \mathrm{~g}$. They were housed in a temperature-controlled room $\left(22^{\circ} \mathrm{C}\right)$ with a light/dark cycle of $12: 12 \mathrm{~h}$ (lights on from 07:00 to 19:00 h). Food and water were given ad libitum. All experiments were carried out according to the guidelines on the ethical use of animals from the European Communities Council Directive of 24 November 1986 (86/609/ EEC) and from the National Ministry of Health (D.M. $222 / 2008)$.

\section{Behavioral characterization of seizure attacks}

The behavior of 14-day-old, 20-day-old and 2-month-old mice was video-recorded for $4 \mathrm{~h}$ every day for 5 days in order to monitor epileptic activity in $B s n$ mutants. The animals were placed in a soundproof room between 11:00 and 15:00 $\mathrm{h}$ with the light on, and recorded through a video camera interfaced with a computer. Videos were stored and analysed offline, and the frequency and duration of attacks were scored.

\section{Electrophysiological experiments}

Adult mice (2-3 months old, weighting 23-28 g) were used for all experiments. Animals were killed by cervical dislocation, in order to obtain coronal corticostriatal slices for electrophysiological recordings (Calabresi et al., 1992, 2000). The slices (200-300 $\mu \mathrm{m})$ were prepared from tissue blocks of the brain with the use of a vibratome. A single slice was transferred to a recording chamber and submerged in continuously flowing $\mathrm{Krebs}$ solution $\left(33^{\circ} \mathrm{C}, 2-\right.$ $3 \mathrm{~mL} / \mathrm{min}$ ) gassed with $95 \% \mathrm{O}_{2}$ and $5 \% \mathrm{CO}_{2}$. The composition of the control solution was $126 \mathrm{mM} \mathrm{NaCl}, 2.5 \mathrm{mM} \mathrm{KCl}, 1.2 \mathrm{mM}$ $\mathrm{MgCl}_{2}, 1.2 \mathrm{mM} \mathrm{NaH} \mathrm{PO}_{4}, 2.4 \mathrm{mM} \mathrm{CaCl}, 11 \mathrm{mM}$ glucose, and $25 \mathrm{mM} \mathrm{NaHCO}$. In all experiments, the intracellular recording electrodes were filled with $2 \mathrm{M} \mathrm{KCl}(30-60 \mathrm{M} \Omega)$. Signals were recorded utilizing an Axoclamp 2B amplifier (Axon Instruments, Foster City, CA, USA), displayed on a separate oscilloscope, and stored and analysed on a digital system (PClAMP 9; Axon
Instruments). For synaptic stimulation, bipolar electrodes were used. These stimulating electrodes were located in the white matter between the cortex and the striatum to activate corticostriatal fibers. For the long-term potentiation (LTP) protocol, at the beginning of intracellular recordings, magnesium ions were omitted from the medium to increase the $N$-methyl-D-aspartate (NMDA)-mediated component of the excitatory postsynaptic potential (EPSP). As conditioning tetanus [high-frequency stimulation (HFS)], we used three trains (duration, $3 \mathrm{~s}$; frequency, $100 \mathrm{~Hz}$; intervals, $20 \mathrm{~s}$ ). During tetanic stimulation, the intensity was increased to suprathreshold levels. In a subset of experiments, variations in the EPSP amplitude in response to the increasing stimulus intensity were studied. Input-output responses were plotted and fitted by a sigmoidal function, and then compared by two-way ANOVA for statistical significance. Quantitative data on EPSP modifications induced by tetanic stimulation are expressed as a percentage of the controls, the latter representing the mean of responses recorded during a stable period (15-20 $\mathrm{min})$ before the tetanus. Values given in the text and in the figures are mean \pm SEM of changes in the respective cell populations. Two-way ANOVA was used; this was followed by Bonferroni post hoc test for comparisons between genotypes or Student's $t$-test to compare the means between pre- and post-tetanic stimulation.

\section{Golgi-Cox impregnation of brain tissue}

Mice were anesthetized with chloral hydrate $(400 \mathrm{mg} / \mathrm{kg})$ and perfused intracardially with $0.9 \%$ saline. The brains were dissected, and impregnated using a standard Golgi-Cox solution (1\% potassium dichromate, $1 \%$ mercuric chloride, and $0.8 \%$ potassium chromate), according to a previously described method (Glaser \& Van der Loos, 1981). The brains immersed in the Golgi-Cox solution were stored at room temperature for 6 days, immersed in a sucrose solution $(30 \%)$ for 2 days, and sectioned coronally $(100 \mu \mathrm{m})$ using a vibratome. Sections were mounted on gelatinized slides, stained according to a previously described method (Gibb \& Kolb, 1998), and covered with Permount solution.

\section{Spine density}

Measurements were performed on MS neurons lying in the dorsolateral striatum. Three spiny neurons within each hemisphere were selected. As no interhemispheric difference was detected, the data were pooled together so that six neurons per striatum were considered in each animal. Fully impregnated neurons were first identified under low magnification $[\times 20$; numerical aperture (NA), 0.5]. Subsequently, spines were analysed/counted under a higher magnification $(\times 63$; NA, $0.75)$. Measurements were performed on each neuron and for three dendrites; five $20-\mu \mathrm{m}$ dendrite segments lying on the focal plane (Leuner et al., 2003) were randomly selected. Segments were sampled $50 \mu \mathrm{m}$ away from soma to exclude the spine-depleted zone arising from the cell body. The average spine density (number of spines per $10 \mu \mathrm{m}$ of dendrite length) was estimated by focusing in and out with the fine adjustment of the microscope (Leica DMLB, Wetzlar, Germany). All protrusions were counted as spines if they were in direct contact with the dendritic shaft. As this method has been proven to give reliable results (Horner \& Arbuthnott, 1991), no attempt was made to introduce a correction factor for hidden spines. All measurements were performed by an experimenter blind to the experimental condition of the animal under examination, and analysed by ANOVA. 


\section{Dendrite branching}

For the branching analysis, three basal dendrites for every neuron were classified by using the centrifugal method (Uylings et al., 1986). The branches arising from the soma were numbered as branch order 1 . Bifurcations on order 1 branches were numbered as branch order 2. In our Golgi-Cox preparations, the maximal branch order reached 6 . The complexity of basal dendrite branching was estimated by counting the number of branches on each dendrite. Data were expressed as the mean number of branches (order $>1$ ) per dendrite, and analysed by ANOvA.

\section{Spine morphology}

The morphology of up to 35 spines on a dendrite segment starting $50 \mu \mathrm{m}$ out from the soma was determined under high magnification $(\times 1000$; NA, 1.25$)$. The spines were placed into five spine maturity categories, according to Irwin et al. (2001): (i) filopodia (narrow neck, no head); (ii) thin spines (narrow neck, small head); (iii) mushroom spines (long neck, large head); (iv) stubby spines (short neck with a sizeable head); and (v) multiple-head spines (short neck, multiple head). The frequency of each spine morphology type encountered for each animal was converted by means of a fixed angular correction factor, and compared across groups by ANOVA analysis.

\section{Immunohistochemistry and unbiased quantification}

Forty-micrometer-thick coronal sections were cut on a microtome (Microm, Walldorf, Germany), and collected in sequence in 24-well plates containing $1 \mathrm{~mL}$ of phosphate buffer (PB). Sections were processed free-floating for PV immunohistochemistry: following three rinses in $\mathrm{PB}(\mathrm{pH} 7.4)$, endogenous peroxidase activity was quenched for $30 \mathrm{~min}$ in $0.3 \% \mathrm{H}_{2} \mathrm{O}_{2} / \mathrm{PB}$. After being rinsed four times in $\mathrm{PB}$, sections were preincubated in 3\% normal donkey serum (NDS) $/ 0.3 \%$ Triton X-100/PB for $45 \mathrm{~min}$, and transferred to a $1: 500$ dilution of primary anti-rat $\mathrm{PV}$ serum raised in rabbit (Swant, Bellinzona, Switzerland) in $1 \%$ NDS $/ 0.3 \%$ Triton X-100/PB. Following overnight incubation at $4{ }^{\circ} \mathrm{C}$, sections were rinsed four times in $\mathrm{PB}$, and incubated in a $1: 500$ dilution of biotinylated anti-rabbit IgG raised in donkey (Jackson Immunoresearch Laboratories, Inc., West Grove, PA, USA) in $1 \% \mathrm{NDS} / 0.3 \%$ Triton $\mathrm{X}-100 / \mathrm{PB}$ for $1.5 \mathrm{~h}$, and rinsed twice in $\mathrm{PB}$. The sections were then transferred to a Vectastain $\mathrm{ABC}$ kit (Vector, Peterborough, UK) in phosphate-buffered saline for $1 \mathrm{~h}$. A $3,3^{\prime}$-diaminobenzidine kit (Vector) served as chromogen in the subsequent visualization reaction. Sections were mounted on gelatincoated slides, left to dry overnight, dehydrated in increasing alcohol concentrations $(75 \%, 95 \%, 100 \%)$, and immersed in xylene. Coverslips were mounted with Eukitt (Labonord, Villeneuve d'Ascq, France). To obtain an unbiased estimate of the total number of neurons, we used the dissector principle and random systematic sampling (Sterio, 1984; Coggeshall, 1992). Stereology analysis software (MERCATOR; Explora Nova, La Rochelle, France) was used to perform unbiased stereological counts of PV-immunoreactive cell bodies in the striatum [for review, see Schmitz \& Hof (2005)]. For the unbiased quantification, a line was drawn around the striatum area of each section (eight sections were counted). For analysis of the various brain sections, the observer was blinded to the mouse number. Cells were counted with a $\times 60$ objective (NA, 0.85) using a Nikon Eclipse E600 microscope (Tokyo, Japan) with a motorized stage $(x, y$, and $z$ ). Random and systematic counting frames $(50 \times 50$, spaced by $200 \mu \mathrm{m})$ were used; only neurons within the frame and focused in $50 \%$ of the thickness were counted on cryosections $(40-\mu \mathrm{m}$ serial sections, one every six sections) obtained from over eight mice through the extent of the striatum. A PV-positive interneuron was defined as a PV-immunoreactive cell body with a clearly visible cell body. PV-positive cells in the striatum were expressed as a total number. The total number of neurons in each striatum was calculated using the formula $N_{\mathrm{t}}=V_{\mathrm{t}} / V_{\mathrm{u}} \times N_{\mathrm{u}}$, where $N_{\mathrm{t}}$ is the total number of PV interneurons in the striatum, $V_{\mathrm{t}}$ is the total volume of the striatum, $V_{\mathrm{u}}$ is the unit volume in which the number of neurons was counted, and $N_{\mathrm{u}}$ is the number of neurons counted in the unit volume. The average of the total amount of cells for each group was analysed with a MannWhitney non-parametric test.

Striatum sections were also processed free-floating for PV and calbindin immunofluorescence. After being rinsed in $\mathrm{PB}$, sections were preincubated in 3\% NDS $/ 0.3 \%$ Triton X-100/PB for $45 \mathrm{~min}$, and transferred to a $1: 500$ dilution of primary anti-rat $\mathrm{PV}$ raised in rabbit (Chemicon, Temecula, CA, USA) and anti-rat calbindin raised in mouse ( $1: 500$; Sigma Aldrich, Milan, Italy) in $1 \% \mathrm{NDS} / 0.3 \%$ Triton X-100/PB. After $2 \mathrm{~h}$ of incubation at $4{ }^{\circ} \mathrm{C}$, sections were rinsed in $\mathrm{PB}$ and incubated in a $1: 200$ dilution of anti-mouse IgG Cy2 raised in donkey and anti-rabbit $\mathrm{IgG} \mathrm{Cy} 3$ raised in donkey (Jackson Immunoresearch Laboratories) in $1 \%$ NDS $/ 0.3 \%$ Triton $\mathrm{X}-100 / \mathrm{PB}$ for $1.5 \mathrm{~h}$, and rinsed in $\mathrm{PB}$. Sections were then mounted in gelatincoated slides, air-dried, and coverslipped with GEL/MOUNT (Biomeda, Foster City, CA, USA). For each section, two pictures of the dorsolateral part of the striatum were taken using $\times 20$ magnification with a CLSM confocal microscope (Zeiss LSM 510). For each mouse, PV-positive and calbindin-positive cells were counted at four different rostrocaudal levels of the striatum. The number of cells was evaluated in each picture acquired, using IMAGEJ software (http://rsb.info.nih. gov/ij). The ratio of the total amount of cells for each labeling was calculated using the formula PV-positive cells/calbindin-positive cells, and compared using a one-way ANOVA.

\section{Western blotting analysis}

Western blotting analysis was performed as described previously, with minor modifications (Gardoni et al., 2006). The Triton-insoluble fraction (TIF) was purified from blind samples of a single striatum of control $(n=4)$ and Bsn mutant animals $(n=4)$, using a previously validated biochemical fractionating method (Gardoni et al., 2006) in the presence of protease inhibitors (Complete ${ }^{\mathrm{TM}}$; Roche Diagnostics, Basel, Switzerland) and phosphatase inhibitors (Sigma, St Louis, MO, USA). Similar protein yields were obtained in TIFs purified from the striatum $(\sim 50 \mu \mathrm{g})$ of both groups. The protein composition of this preparation was tested for the absence of the presynaptic synaptic vesicle marker synaptophysin (Gardoni et al., 2001) and enrichment in the postsynaptic density (PSD) proteins (Gardoni et al., 2006). Samples $(3 \mu \mathrm{g})$ were subjected to sodium dodecylsulfate polyacrylamide gel electrophoresis and electroblotted. Three independent western blotting experiments were run for each TIF preparation. After blocking of non-specific protein interactions with $10 \%$ albumin in Tris-buffered saline (TBS), the nitrocellulose papers were incubated for $2 \mathrm{~h}$ at room temperature with the primary antibodies in $3 \%$ albumin in TBS: NR1 (1 : 1000; Pharmingen, San Diego, CA, USA), NR2A (1 : 1000; Zymed, San Francisco, CA, USA), NR2B (1: 1000; Zymed), GluR1 (1 : 1500; Chemicon), GluR2 (1 : 1500; Chemicon), PSD-95 (1 : 2000; Affinity BioReagents, Golden, CO, USA), SAP97 (1: 1000; StressGen, San Diego, CA, USA), $\alpha$ CaMKII (1 : 3000; Chemicon), p286-CaMKII (1 : 1000; Promega, San Luis Obispo, CA, USA), and actin ( $1: 3000$; Sigma Aldrich, Milan, Italy). After extensive rinsing in TBS $/ 0.1 \%$ Tween-20, the nitrocellulose papers were incubated with horseradish peroxidase-conjugated secondary 
antibodies. Actin was used as loading control in both the homogenate and the TIF. Finally, the antigen-antibody complex was revealed by enhanced chemiluminescence (Amersham Biosciences, Little Chalfont, UK). Quantification was performed with the QUANTITY-ONE computer-assisted imaging system (Bio-Rad, Hercules, CA, USA). Student's $t$-test was used to compare western blotting results from wild-type and Bsn mutant animals.

\section{Drugs}

Sodium valproate (Depakin, $200 \mathrm{mg} / \mathrm{mL}$; Sanofi Aventis, Milan, Italy) was added to drinking water at a concentration of $100 \mathrm{mg}$ / $100 \mathrm{~mL}$ in order to administer a dose of $400 \mathrm{mg} / \mathrm{kg}$. Dizocilpine (MK-801; Tocris, Cookson, UK) was applied by dissolving it to the desired final concentration in Krebs solution and by switching the perfusion from control to drug-containing solution.

\section{Results}

\section{Behavioral characterization of seizure attacks in Bsn mutants}

Video monitoring was performed on 14-day-old, 20-day-old and 2-month-old mice to analyse the seizure phenotype in more detail. When mice were 14 days old, it was possible to observe tremor, brief episodes of head-neck myoclonus, and, more rarely, forelimb myoclonus (Supporting information, Video S1). Twenty-day-old mice showed more characteristic epileptic behavior: tremor, head-bobbing and hypermotility preceded a series of epileptic episodes of forelimb myoclonus associated with rearing, tail myoclonus and tonic extension of forelimbs. When mice were 2 months old, they showed more complex and severe seizures, characterized by head-neck myoclonus, forelimb clonus, jumping, tail clonus, rearing barrel rolling followed by tonic limb extension (more evident for forelimbs), which ended in generalized tonic-clonic seizures (Supporting information, Video S2). Seizures appeared to be more behaviorally severe when observed at age 60 days. Behavioral classification and age of onset of habitual seizures in the mice are shown in Table 1.

\section{Altered synaptic plasticity in MS neurons of Bsn mutant mice}

Twenty-four MS neurons from Bsn mutant mice were discriminated from FS interneurons on the basis of their electrophysiological characteristics, and compared with MS neurons obtained from wildtype littermates $(n=25)$. No significant changes in the input-output curve or the intrinsic membrane properties (membrane potential, input resistance, and firing discharge) of MS neurons were found between the two genotypes (Fig. 1A, supporting Fig. S1A, and Table 2). As

TABLE 1. Behavioral characterization of seizure attacks in Bsn mutant mice at different ages

\begin{tabular}{lllll}
\hline Age & Frequency & $\begin{array}{c}\text { Attacks } \\
\text { per day }\end{array}$ & Duration (s) & Attack type \\
\hline 14 days & $10 / 16$ & Up to 2 & $40.5 \pm 2.0$ & $\begin{array}{l}\text { Myoclonic seizures } \\
\text { 20 days }\end{array} 12 / 16$ \\
Up to 2 & $31.2 \pm 4.0$ & $\begin{array}{c}\text { Generalized } \\
\text { tonic-clonic seizures } \\
\text { Generalized } \\
\text { tonic-clonic seizures }\end{array}$ \\
\hline
\end{tabular}

Frequency of attacks was calculated as the ratio of the number of animals with seizures to the number of animals observed. Values are mean $\pm \mathrm{SEM}$ of the duration of the seizure attacks.
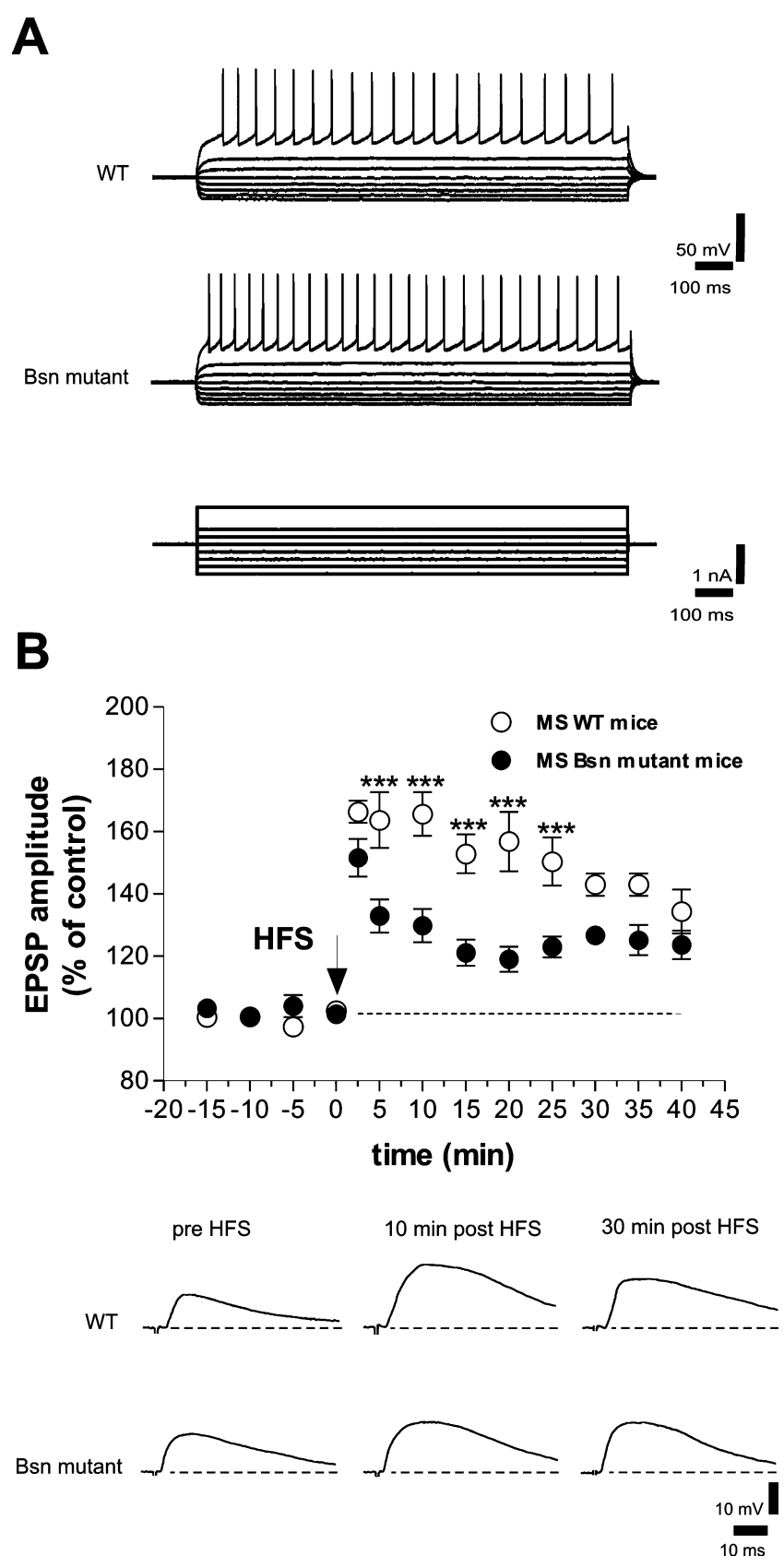

FIG. 1. Electrophysiological characterization of synaptic plasticity in medium spiny (MS) neurons of Bsn mutant mice. (A) Intrinsic and synaptic properties of striatal MS neurons from Bsn wild-type (WT) and mutant mice. The action potential discharge was induced by hyperpolarizing and depolarizing current steps in MS neurons from WT (upper trace) and Bsn mutant mice (lower trace). (B) In the absence of physiological concentrations of external magnesium, high-frequency stimulation (HFS) induced long-term potentiation (LTP) in MS neurons from both mutant and WT mice. Note that although the excitatory postsynaptic potential (EPSP) amplitude during the post-tetanic potentiation (first time point at 2 min after HFS) was comparable between the two genotypes, the amplitude of LTP induced in mutant mice was smaller than in WT mice $(* * * P<0.001)$. The arrows indicate when HFS was delivered. The bottom parts of both A and B show examples of EPSPs recorded in MS neurons from WT and mutant slices immediately before, $10 \mathrm{~min}$ after and $30 \mathrm{~min}$ after HFS.

previously described (Calabresi et al., 1992, 2000), in the absence of magnesium ions, HFS (three trains: frequency, $100 \mathrm{~Hz}$; duration, $3 \mathrm{~s}$; interval, $20 \mathrm{~s}$ ) induces stable LTP of corticostriatal synaptic transmis- 
TABLE 2. Properties of striatal medium spiny (MS) neurons and fast-spiking (FS) interneurons

\begin{tabular}{|c|c|c|c|c|}
\hline & \multicolumn{2}{|l|}{ Wild type } & \multicolumn{2}{|l|}{ Bsn mutant } \\
\hline & MS, $n=25$ & FS, $n=19$ & MS, $n=24$ & $\mathrm{FS}, n=20$ \\
\hline $\begin{array}{l}\text { AP half-width } \\
\text { (ms) }\end{array}$ & $0.62 \pm 0.02$ & $0.57 \pm 0.01$ & $0.60 \pm 0.01$ & $0.55 \pm 0.01$ \\
\hline $\begin{array}{l}\text { AHP amplitude } \\
(\mathrm{mV})\end{array}$ & $15.99 \pm 0.98$ & $21.62 \pm 0.57$ & $17.97 \pm 0.59$ & $22.02 \pm 0.66$ \\
\hline $\operatorname{Rin}(\mathrm{M} \Omega)$ & $33.87 \pm 3.89$ & $37.00 \pm 4.37$ & $35.54 \pm 1.86$ & $39.64 \pm 3.28$ \\
\hline RMP (mV) & $-86.24 \pm 4.00$ & $-76.91 \pm 2.54$ & $-85.05 \pm 1.45$ & $-75.38 \pm 1.49$ \\
\hline
\end{tabular}

Values are mean \pm SEM of the action potential (AP) half-width, the afterpolarization (AHP) amplitude, the input resistance $\left(R_{\text {in }}\right)$, and the resting membrane potential (RMP). No significant differences in these parameters were found between Bsn mutant and wild-type mice for each cell type.

sion. The HFS protocol induced LTP in MS neurons intracellularly recorded from both experimental groups. Interestingly, however, the amplitude of the early phase (5-25 min after the tetanus) of LTP observed in MS neurons from mutant mice was lower than that in wild-type animals (mutant, $n=6$; wild type, $n=5 ; P<0.001$ ) (Fig. 1B). Detailed analysis of responses to tetanic stimulation (depolarization area and amplitude; data not shown), and post-tetanic potentiation (see first time point after the tetanus in Fig. 1B) showed that there were no differences in the induction of post-tetanic potentiation between groups. Moreover, bath application of the NMDA receptor antagonist MK-801 $(10 \mu \mathrm{M})$ blocked LTP in both mutant and wild-type mice ( $n=3$ for each group; data not shown).

\section{Morphological analysis of MS neurons in mice lacking Bsn}

To examine whether structural changes were involved in the marked decrease in LTP at corticostriatal synapses found in Bsn mutants, we performed a morphological analysis of Golgi-stained striatal MS neurons. Although the loss of Bsn was not found to affect spine density (data not shown), it was associated with changes in the proportion of mature vs. immature spines, counted on apical dendrite segments, towards spines characterized by fewer multiple-head, mushroomstructured spines and more thin and elongated ones as compared with the wild type (genotype $\times$ spine category interaction effect: $\left.F_{4,32}=4.10 ; P<0.01\right)$. In particular, post hoc comparison within each category, revealed that the frequency of the thin spines category in $B s n$ mutants was significantly higher than in wild-type mice (NewmanKeuls test; $P<0.05$ ) (Fig. 2B, left). However, examination of the dendritic arbors revealed a higher number of branches per dendrite on MS neurons of Bsn mutant mice than on those of wild-type mice (ANOVA: $F_{1,46}=4.14, P<0.05$ ) (Fig. $2 \mathrm{~B}$, right).

\section{Altered distribution of NMDA receptor subunits in epileptic animals}

As LTP in the striatum, as well as in other brain areas, requires activation of NMDA receptors (Calabresi et al., 1992; Bortolotto \& Collingridge, 1998), the altered amplitude of LTP in Bsn mutant mice is likely to reflect an alteration in NMDA receptor-associated signaling elements. Because the NMDA receptor complex is highly expressed in the PSD, we first measured protein levels of NMDA receptor subunits and other PSDassociated signaling proteins in both striatal homogenates and purified TIFs from control and Bsn mutant mice by western blot analysis (Gardoni et al., 2001). Levels of the NMDA receptor subunit NR1,
MAGUK proteins (PSD-95 and SAP97), $\alpha$ CaMKII, p286-(autophosphorylated)- $\alpha$ CaMKII and actin were not altered in striatal homogenates and TIFs from $B s n$ mutant mice $(P>0.05)$ (Fig. 3A), suggesting that the gross composition of the TIF was not affected in Bsn mutant animals. Interestingly, the synaptic levels of NR2A and NR2B showed profound changes, with a significant increase in NR2A $(P<0.05)$ and a concomitant decrease in NR2B $(P<0.01)$ in $B s n$ mutant striata (Fig. 3B). Significant decreases in NR2B levels $(P<0.05)$ were also found in the total homogenate from $B s n$ mutant animals.

\section{Abnormal synaptic potentiation in FS interneurons of Bsn mutant mice}

To study the synaptic plasticity of this neuronal subtype, we characterized FS interneurons recorded from the dorsolateral striatum and tested whether these cells respond to corticostriatal stimulation, which is known to induce synaptic changes in other neuronal subtypes. The intrinsic membrane properties of $20 \mathrm{FS}$ interneurons from Bsn mutant mice were not changed as compared with wild-type mice $(n=19)$ (Fig. 4A; Table 2). Input-output relationships were also similar between the two genotypes $(P>0.05$; wild type, $n=9$; mutant, $n=11$ ) (supporting information Fig. S1B). Their action potentials showed typical fast, deep afterhyperpolarization, and the firing pattern varied from tonic to interrupted (Kawaguchi, 1993; Kawaguchi et al., 1995; Koos \& Tepper, 1999; Bracci et al., 2002). Consistent with previous studies (Kawaguchi, 1993; Bracci et al., 2002), their resting membrane potential was $-76.91 \pm 2.54 \mathrm{mV}$, and the input resistance was $37.00 \pm 4.37 \mathrm{M} \Omega$. Moreover, FS interneurons showed a characteristic longer duration of evoked EPSP (EPSP decay slope: wild type, $-0.14 \pm 0.01, n=14$; mutant, $-0.13 \pm 0.01, n=19$ ) as compared with MS neurons (EPSP decay slope: wild type, $-0.23 \pm 0.02, n=15, \quad P<0.001$ for MS vs. FS; mutant, $-0.22 \pm 0.02, n=23, P<0.001$ for MS vs. FS). Interestingly, in the absence of magnesium ions and following HFS, FS interneurons from Bsn mutant mice showed a short-term increase in synaptic strength, whereas neurons from wild-type mice showed either no change or a small transient synaptic depression $(n=6$, mutant and wild type, 5 and 10 min after the tetanus, $P<0.001$ and $P<0.01$, respectively, mutant vs. wild-type) (Fig. 4B and C). Pharmacological manipulations of glutamatergic receptors with the NMDA antagonist MK-801 indicated that, similar to what was observed in MS neurons (Calabresi et al., 1992), the induction of the potentiation observed in FS interneurons was NMDA-dependent. Interestingly, pharmacological antagonism of NMDA receptors not only blocked synaptic potentiation, but even caused a depression in FS interneurons from Bsn mutant mice $(n=5$, $P<0.001,5-10,20 \mathrm{~min}$ after tetanus, $P<0.01,15 \mathrm{~min}$ after tetanus, $P<0.05,25-30$ min after tetanus, mutant + MK-801 vs. mutant) (Fig. 4B and C).

\section{Increased number of PV-positive cells in Bsn mutant mice}

PV immunohistochemistry in the striatum was investigated in order to quantify the amounts of striatal FS interneurons in wild-type and Bsn mutant mice (Fig. 5A). Comparison of striatal PV-positive cell quantification between the two genotypes (Fig. 5B) showed a higher number of FS interneurons in Bsn mutant mice than in wildtype mice (Mann-Whitney non-parametric test; mutant, $n=4$; wild type, $n=4 ; P<0.001)$. Taken together, these findings suggest that Bsn mutation-induced epilepsy is associated with profound structural and functional modifications in both the neuronal subtypes analysed. 
A

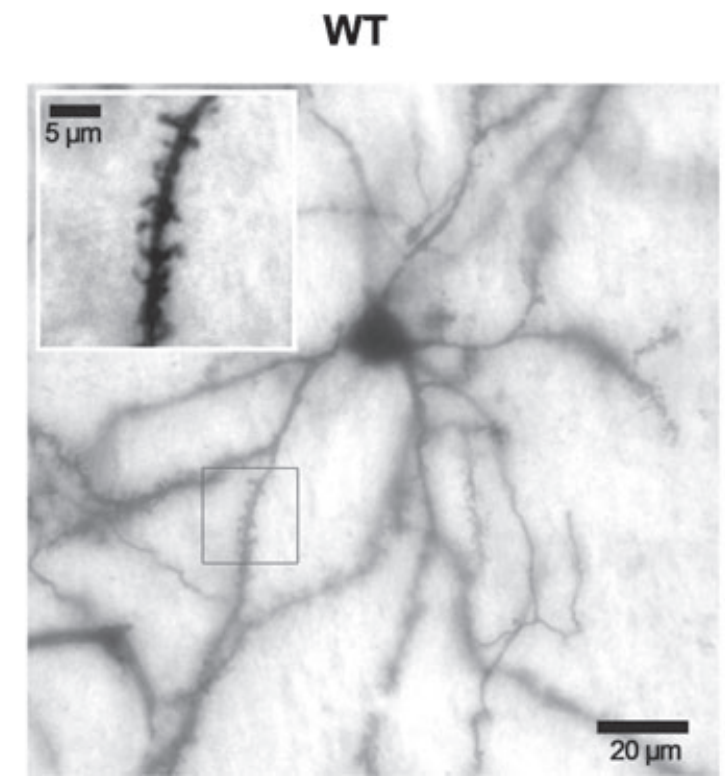

Bsn mutant

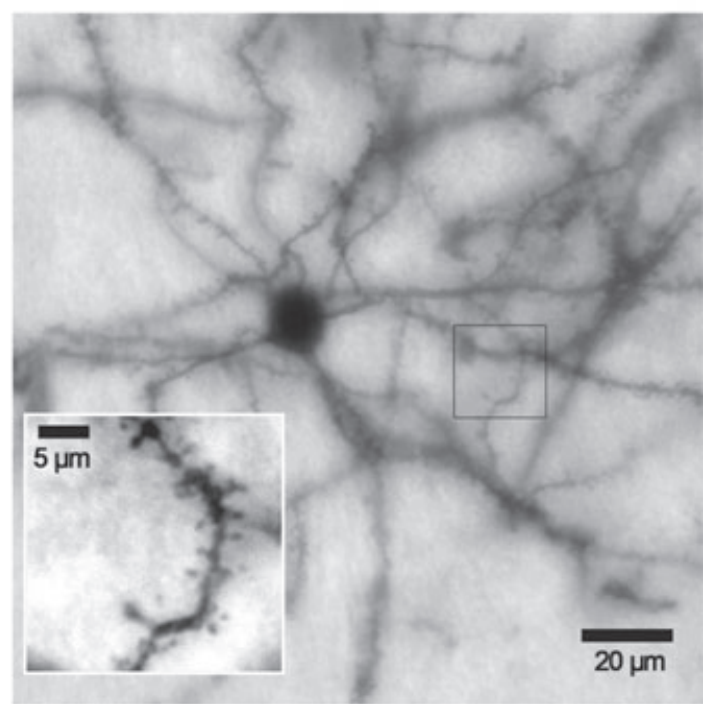

B
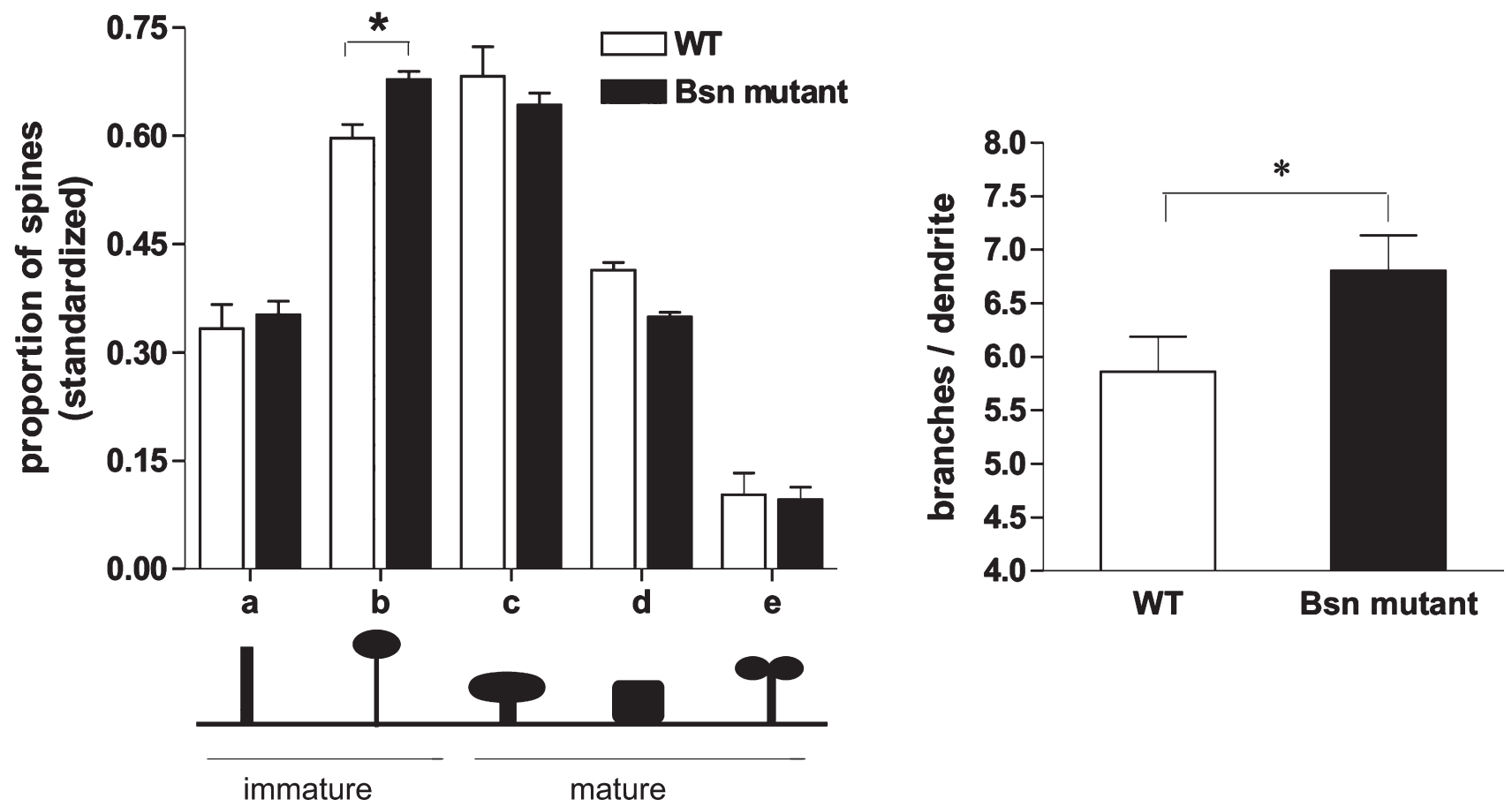

FIG. 2. Increase in dendrite branching and shift in proportion of immature vs. mature spines in medium spiny (MS) neurons. (A) Examples of typical spine morphologies and dendrite branching on Golgi-impregnated MS neurons from Bsn mutant mice (right) and wild-type (WT) mice (left). (B) The histogram on the left shows the distribution of spine morphology types encountered on MS dendrites. Bsn mutant mice exhibited more longer and fewer shorter spines in the striatal MS neurons analysed, specifically within the thin spines category $\left({ }^{*} P<0.05\right)$. The graph on the right shows the averaged number of branches encountered on each MS dendrite. MS neurons of Bsn mutant mice were characterized by increased branching as compared with those of WT mice $(P<0.05)$.

\section{Chronic VPA treatment reduced epileptic seizures and} normalized synaptic plasticity and NMDA subunit composition in Bsn mutants

In order to distinguish between the contribution of Bsn mutation and the effect exerted by chronic epileptic seizures on corticostriatal synaptic plasticity and striatal PSD composition, VPA (400 mg/kg,
$100 \mathrm{mg} / 100 \mathrm{~mL}$ of water), a broad-spectrum AED, was given orally to heterozygous females, in order to treat pups via maternal breast milk, from postnatal day $(\mathrm{P}) 0$ to weaning (P21). Treatment was extended into adulthood at the same dose previously used with the dams. Early exposure to VPA significantly reduced the postnatal mortality associated with the epileptic syndrome in mutants (Fig. 6A, left $)\left(\chi^{2}=6.47 ; P<0.05\right)$. Behavioral monitoring of the surviving 


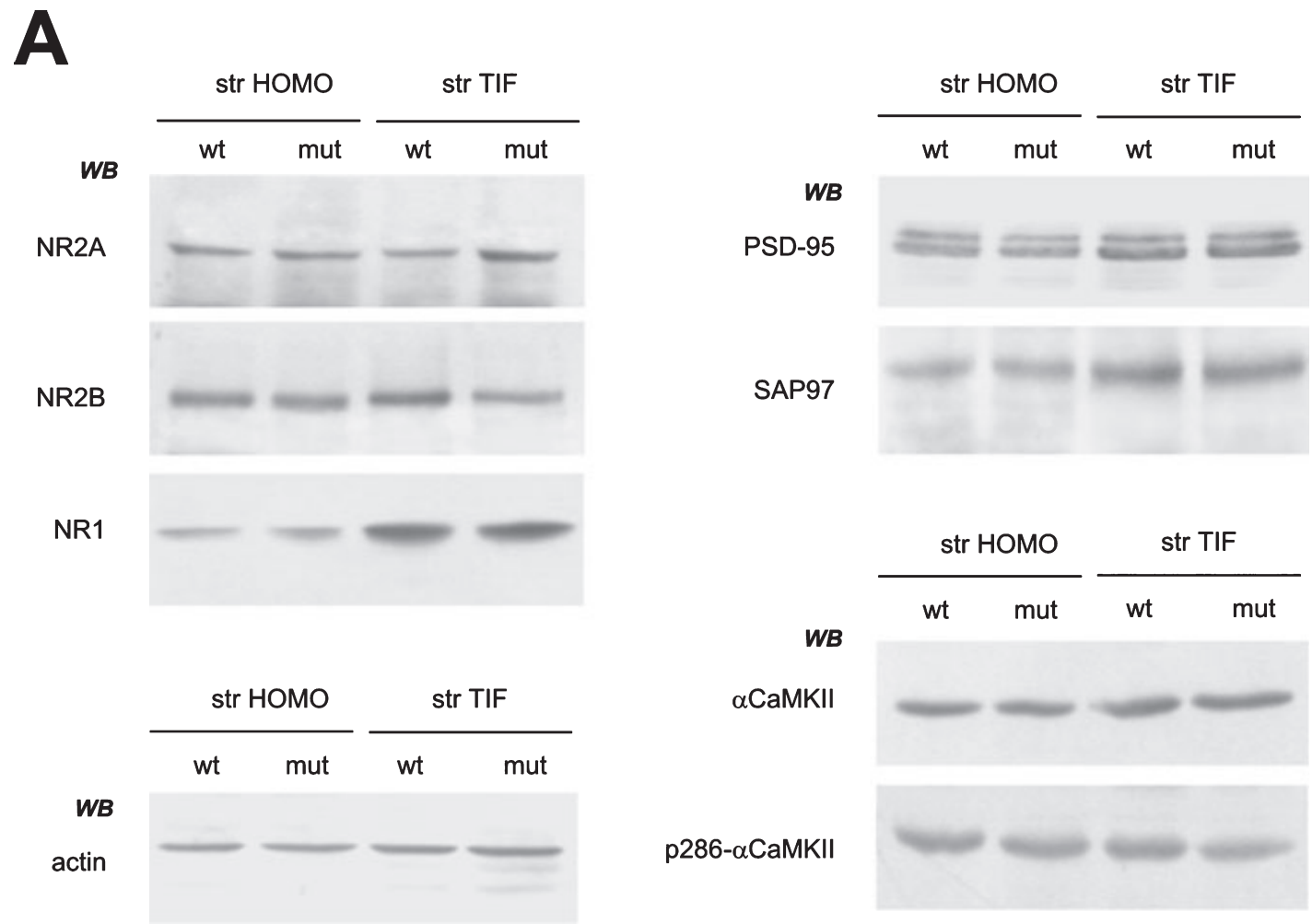

B

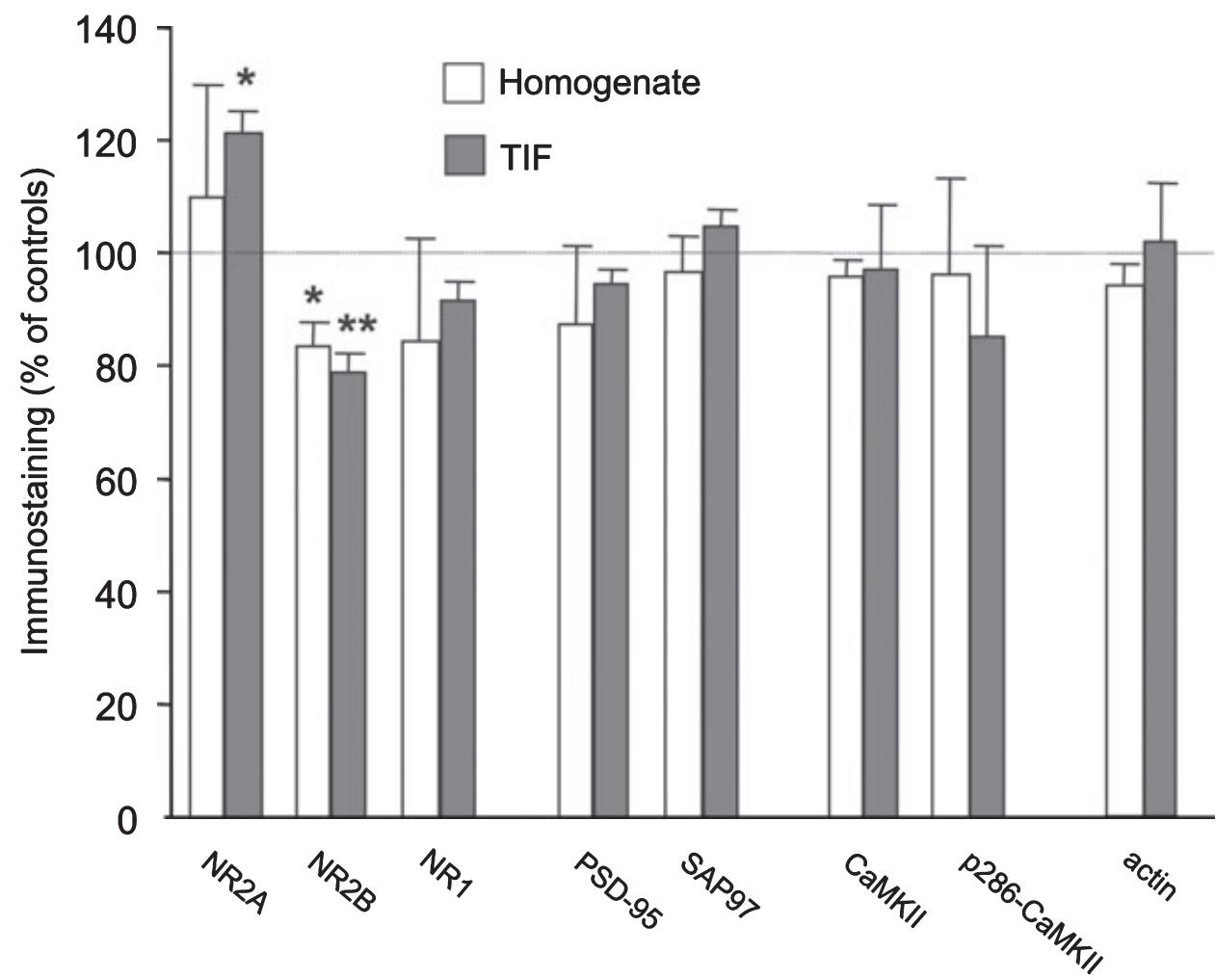

FIG. 3. Characterization of the $N$-methyl-D-aspartate (NMDA) receptor complex in Bsn mutant mice striatum. (A) Histograms show the quantification of results of western blotting (WB) performed in homogenates (HOMO) and Triton-insoluble fractions (TIF) $[P>0.05$, PSD-95, SAP97, and $\alpha$ CaMKII (total and p286); $* P<0.05, \mathrm{NR} 2 \mathrm{~A} ; * * P<0.01, \mathrm{NR} 2 \mathrm{~B} ;{ }^{*} P<0.05$, NR2B (HOMO)]. (B) Striatal (str) homogenates and TIFs from wild-type (wt) and $B s n$ mutant (mut) mice striata were analysed by western blot analysis with NMDA receptor subunits (NR1, NR2A, NR2B), MAGUK proteins (PSD-95, SAP97 and SAP102), $\alpha$ CaMKII (total and p286) and actin antibodies. The same amount of protein was loaded per lane, and actin was used as loading control in both homogenates and TIF fractions. 
A
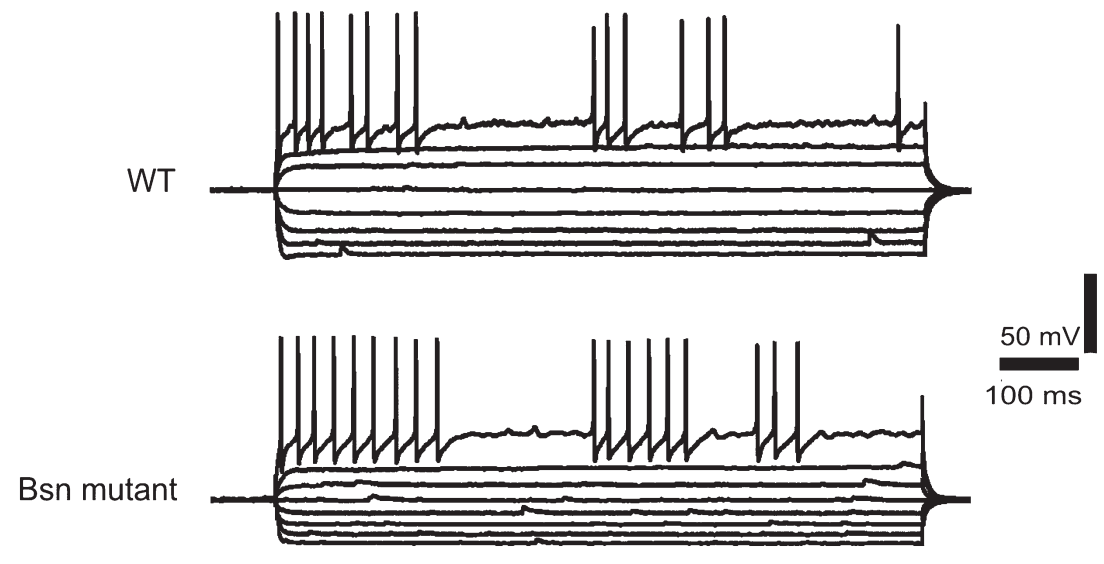

B
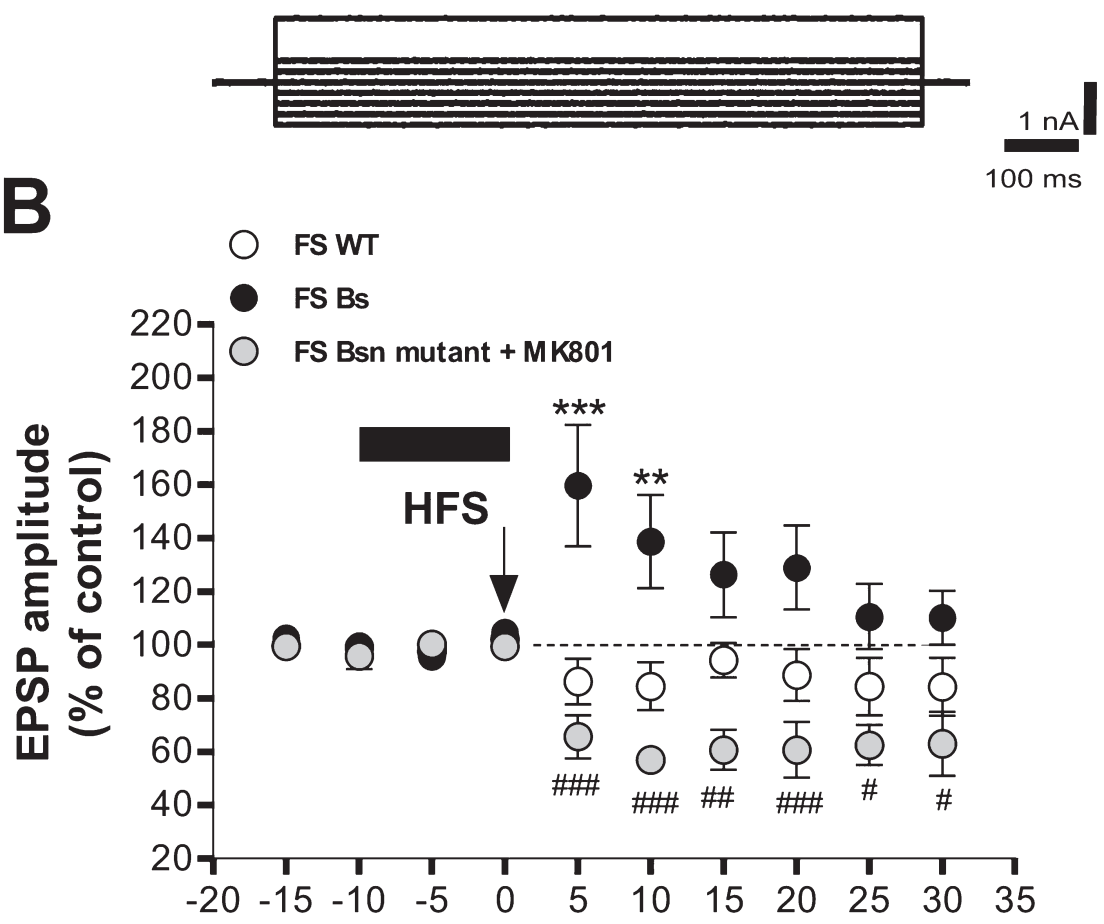

$\mathrm{C}$

time (min)
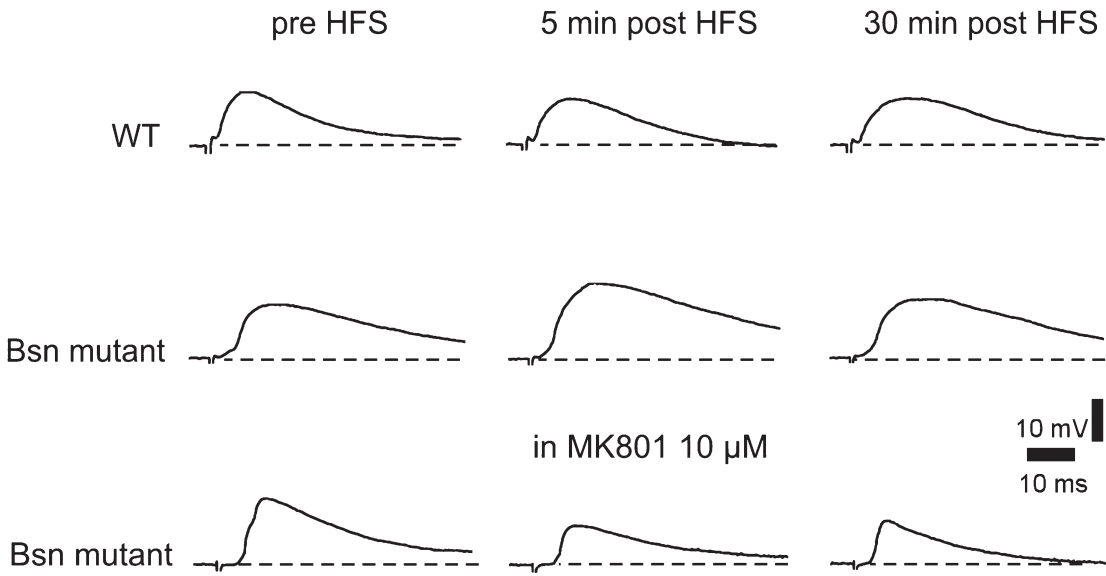
animals showed that VPA was able to reduce the frequency of epileptic seizures by $58 \%$ (Fig. $6 \mathrm{~A}$, right) $\left(t_{10}=1.99 ; P<0.05\right)$. Intracellular recordings from corticostriatal slices showed that LTP at $25 \mathrm{~min}$ after the tetanus was rescued in MS neurons from treated mutant mice (Bsn mutant vs. Bsn mutant with VPA, $P<0.01$ ), and no effect on treated wild-type animals was observed (Fig. 6B, left). Moreover, striatal FS interneurons from VPA-exposed epileptic mice failed to show the postsynaptic potentiation previously observed in naïve mutants (Bsn mutant vs. Bsn mutant with VPA, $P<0.01$ ) (Fig. 6B, right). Analysis of striatal PSD composition revealed that the abnormal ratio between the NR2A and NR2B subunits was normalized by VPA treatment in homozygous mutants $(P<0.01)$, whereas the other components were unaffected by drug administration (Fig. 6C).

\section{Chronic VPA failed to reverse morphological alterations in Bsn mutants}

The morphological pattern associated with $B s n$ deletion was analysed following VPA administration. In Bsn mutants, neonatal exposure to the AED was not able to prevent extensive branching (genotype main effect, $F_{1,12}=5.93 ; P<0.05$; genotype $\times$ treatment interaction effect, $\left.F_{1,12}=0.02 ; P>0.05\right)$ and the spine immaturity of MS neurons (genotype $\times$ spine category interaction effect, $F_{4,64}=0.01 ; P<0.05$; treatment main factor and relative interactions, $P>0.05$ ) observed in naïve animals (Fig. 7). Moreover, immunohistochemical analysis of striatal tissues showed that VPA failed to prevent or reverse the PV overexpression associated with the epileptic condition. In fact, the amounts of FS interneurons and MS neurons were not affected by VPA treatment, as shown by the ratio between the numbers of the two neuronal subtypes, which was found to be unchanged in both genotypes (genotype main effect, $F_{1,8}=42.23$, treatment main factor and interaction, $P>0.05$ ) (Fig. 8).

\section{Discussion}

The main findings of this work are that striatal neuronal subtypes are differentially sensitive to frequent seizures triggered in the brain of Bsn mutant mice, and that synaptic plasticity changes develop in response to early-onset epilepsy in these mice. Interestingly, functional but not structural alterations in Bsn mutants were prevented by chronic antiepileptic treatment with VPA, suggesting that the observed electrophysiological and molecular changes are secondary to the seizure activity rather than being directly induced by the lack of functional Bassoon. Conversely, as morphological alterations were not found to be prevented by chronic antiepileptic treatment, it is possible to hypothesize that they represent a direct effect of the abnormal genotype of these mice.

In this model, early-onset epileptic seizures are associated with an altered LTP time course and a reorganization of spine morphology and dendrite connectivity in MS neurons. Along with the alterations observed in MS projecting neurons, we found that FS interneurons of mutant mice express a short-term potentiation that is not present in FS interneurons of wild-type mice. The expression of this form of plasticity in FS cells, as well as the increased number of these GABAergic interneurons, might reflect upregulation of the feedforward inhibition within the striatum of the mutant mice, and it might represent a compensatory mechanism aimed at limiting striatal damage following repetitive seizures.

We found that in Bsn mutant mice, epileptic attacks developed early, around P14, as myoclonic seizures, and evolved into generalized tonic-clonic seizures in adult mutants. This finding is consistent with the epileptic phenotype observed in other rodent experimental models (Chapman et al., 1987; Engstrom \& Woodbury, 1988; Musumeci et al., 2000; De Sarro et al., 2004).

In $B s n$ mutant mice, as in other epileptic conditions, cortical neurons engaged in paroxysmal activity might lead to alterations in corticostriatal pathway activity. Increasing attention has recently been paid to the changes occurring through the corticostriatal projections during pathological and physiological activity originating from the cortex at the level of different neuronal subtypes (Bracci et al., 2004; Slaght et al., 2004; Mallet et al., 2005). It is known that dendritic spines represent the principal site of synaptic input and therefore play a key role in activity-dependent synaptic plasticity in MS neurons (Fiala et al., 2002; Tada \& Sheng, 2006).

In epileptic patients and in experimental in vivo and in vitro models of epilepsy, there is a marked loss of dendritic spines in the brain foci of seizures, and this is often associated with distortion of the shape of the remaining spines and degeneration (Fiala et al., 2002). In line with these observations, we have shown that the absence of functional Bassoon is associated with a shift in the proportion of mature vs. immature spines counted on apical dendrite segments, as well as an increase in the branching of MS neurons of mutant mice as compared with wild-type mice. Given the role of Bassoon in synapse maturation and neuronal connectivity, it is more reasonable to consider the functional deletion of this protein as the possible cause of these morphological alterations rather than the epileptic activity itself. In particular, initial morphological alterations might lead to the establishment of a pathological substrate, which, in turn, might favor recurrence of seizures, triggering a vicious circle.

On this view, abnormal striatal plasticity could be interpreted as a consequence of repeated seizures. It is possible to hypothesize that the impairment of LTP in MS neurons is the result of altered NMDA receptor subunit composition. Indeed, activation, correct assembly and localization of the NMDA receptors are essential for striatal LTP (Picconi et al., 2004). Interestingly, previous reports demonstrated that the PSD, a synaptic compartment highly enriched in ionotropic glutamate receptors (Kim \& Sheng, 2004), is altered in brain areas where the seizure activity is more pronounced (Wyneken et al., 2001, 2003; Finardi et al., 2006). It has been recently postulated that regulation of the NR2A/NR2B ratio plays a pivotal role in the control of cortical synaptic plasticity (Yashiro \& Philpot, 2008). Moreover, two recent studies have shown that inactivation of the NR2B subunit is sufficient to selectively abolish hippocampal LTP (Bartlett et al., 2007), and that an appropriate synaptic localization of

FIG. 4. N-Methyl-D-aspartate (NMDA)-dependent short-term plasticity in fast-spiking (FS) interneurons of Bsn mutant mice. (A) Intrinsic and synaptic properties of striatal FS interneurons. Action potential discharges were induced by hyperpolarizing and depolarizing current steps in FS interneurons from wild-type (WT) (upper trace) and Bsn mutant mice (lower trace). (B) High-frequency stimulation (HFS; arrow) induced a synaptic potentiation that lasted 15-20 min in FS interneurons of Bsn mutant mice. Conversely, no potentiation was observed in WT mice $(n=6$, mutant and WT, 5 and 10 min after tetanus, $* * * P<0.001$ and $* * P<0.01$, respectively, mutant vs. WT). Note that incubation of the $B s n$ mutant slices with the NMDA receptor antagonist MK801 reversed potentiation into a synaptic depression $\left(n=5,{ }^{\# \# P} P<0.001,5-10,20\right.$ min after tetanus, ${ }^{\#} P<0.01,15$ min after tetanus, ${ }^{\#} P<0.05,25-30$ min after tetanus, mutant + MK-801 vs. mutant). (C) Traces represent examples of excitatory postsynaptic potentials (EPSPs) from FS interneurons recorded intracellularly in WT (upper traces), Bsn mutant (middle traces) and Bsn mutant mouse slices with application of MK801 (lower traces). 

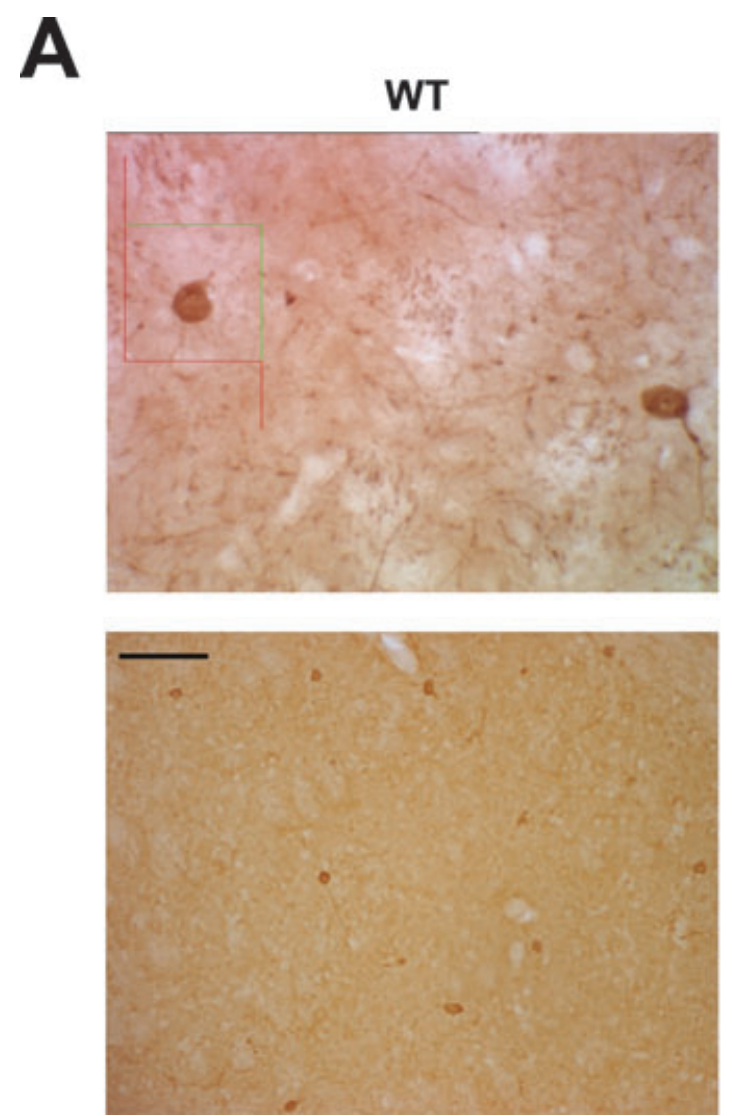

\section{Bsn mutant}
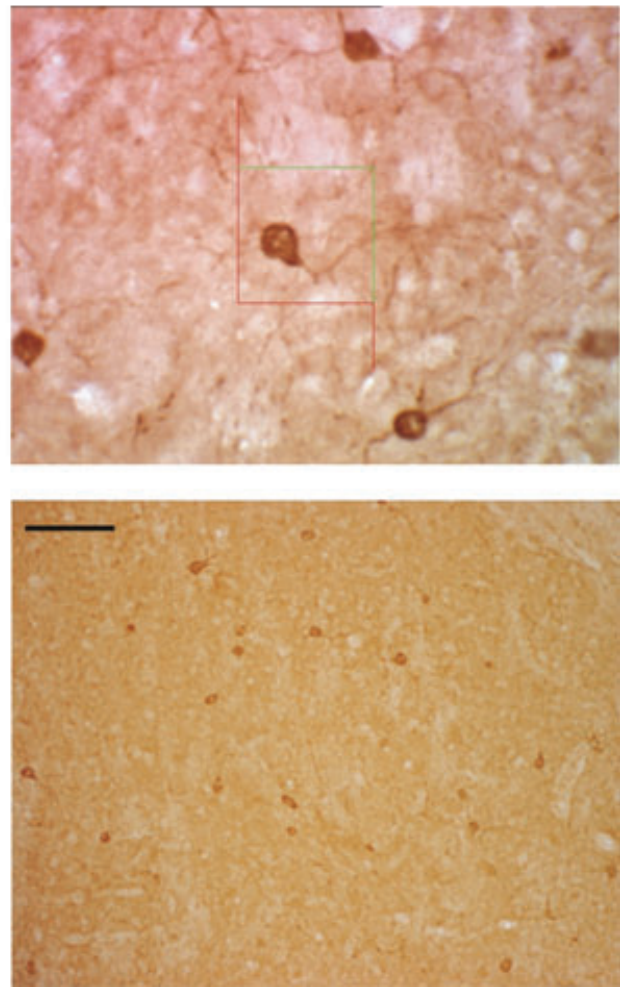

B

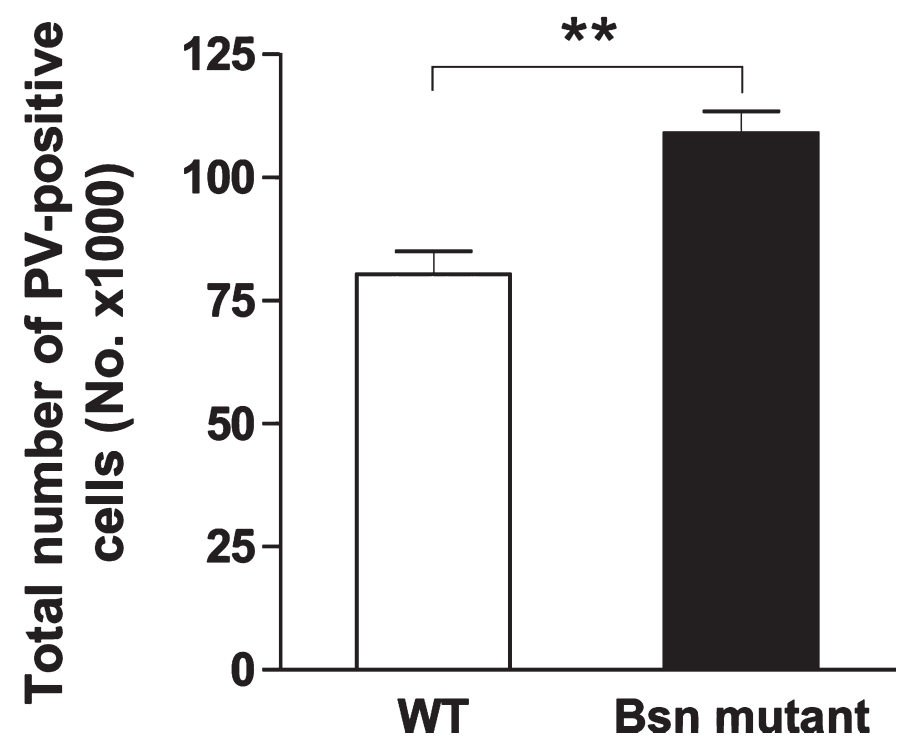

FIG. 5. Increased number of parvalbumin (PV)-positive cells in $B s n$ mutants. (A) PV immunohistochemical investigations were performed in the striatum in order to quantify the amounts of striatal fast-spiking (FS) interneurons in wild-type (WT) mice (right) and Bsn mutant mice (left). Upper panels correspond to $\times 60$ magnification; the squares are the dissectors $(50 \times 50 \mu \mathrm{m})$ used for the unbiased counting. Lower panels correspond to $\times 20$ magnification; scale bar $=100 \mu \mathrm{m}$. (B) Comparison of striatal PV-positive cell quantification between the two genotypes showed a higher number of FS interneurons in Bsn mutant mice than in WT mice $(* * P<0.01)$, suggesting a compensatory mechanism of FS interneurons in the striatum of these mutant animals.

NR2B-containing receptor is critically required for LTP induction in hippocampal slices (Gardoni et al., 2009). Accordingly, in Bsn mutants, we observed altered NMDA composition in the striatal
PSD. In particular, the levels of NR2A and NR2B were modified, with a significant increase in NR2A/NR2B ratios in Bsn mutant striata. 

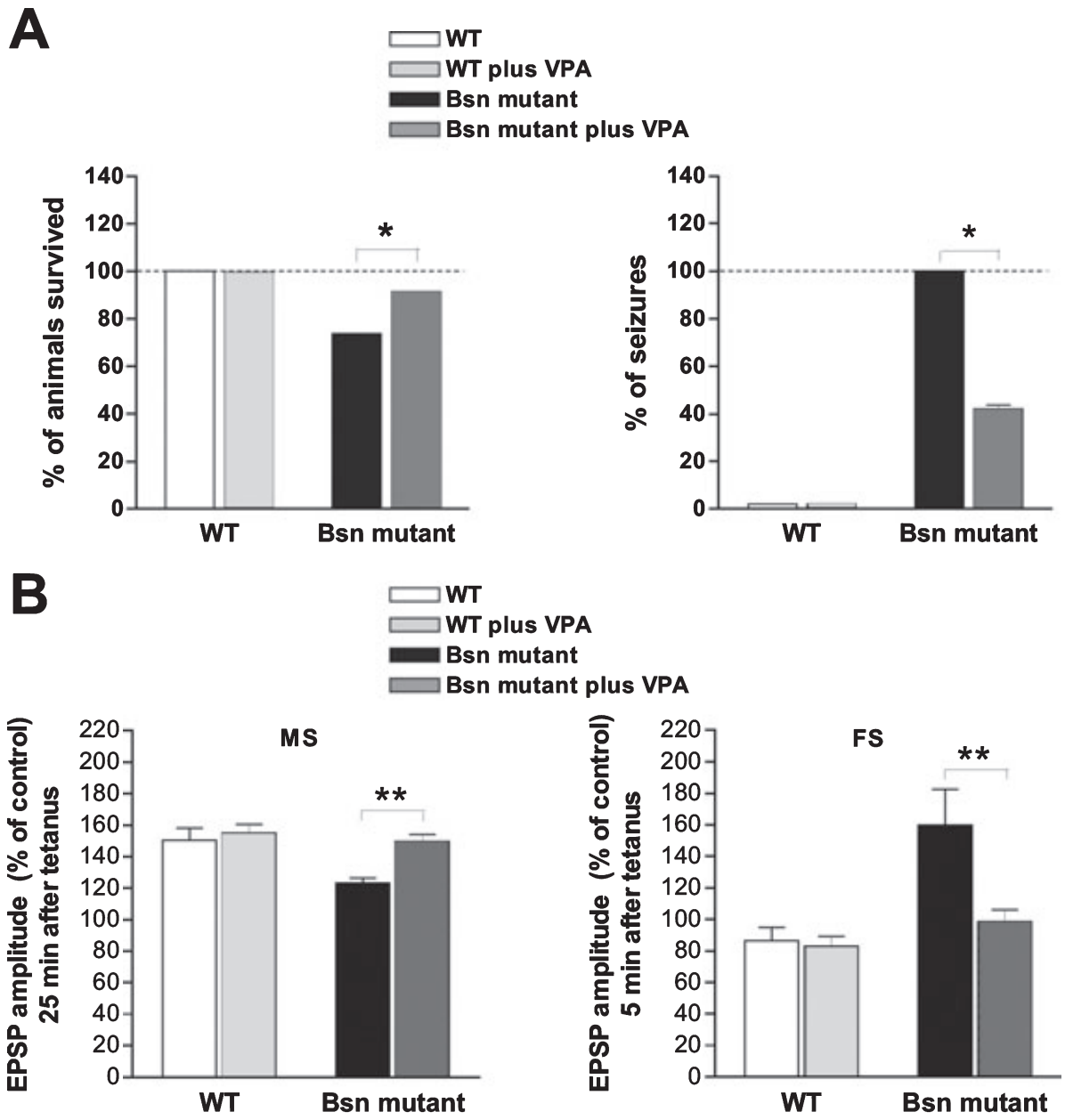

C
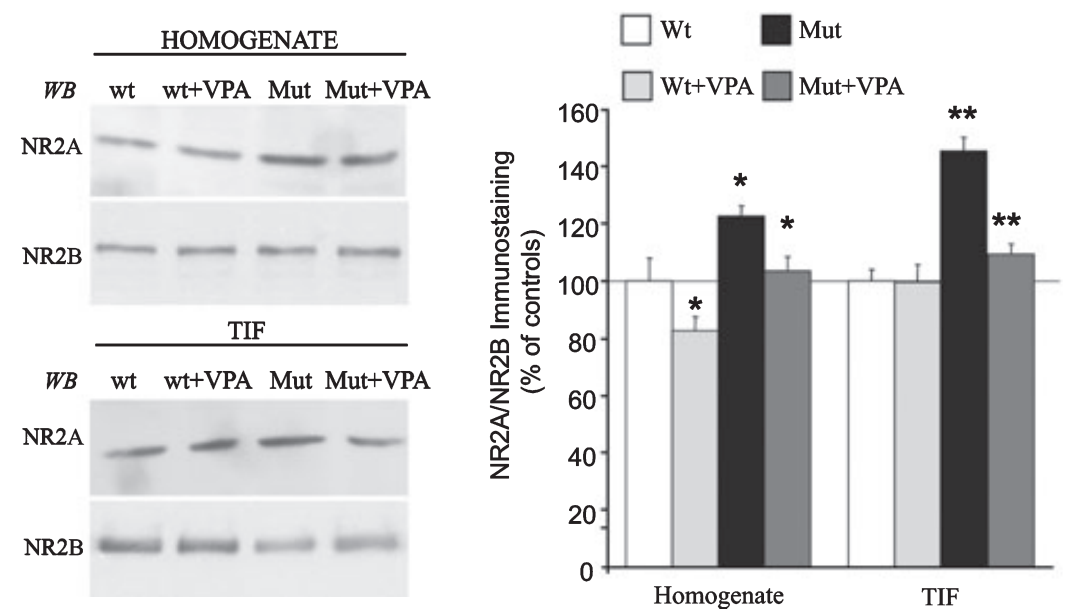

FIG. 6. Valproic acid (VPA) reduced the number of seizures and rescued synaptic plasticity and $N$-methyl-D-aspartate (NMDA) receptor subunit composition. (A) The histograms show that chronic administration of VPA induced a significant increase in survival rate (left) $(* P<0.05)$ and reduced the number of epileptic attacks in mutant mice (right) $(* P<0.05)$. (B) In the medium spiny (MS) neurons of treated Bsn mice, long-term potentiation (LTP) amplitude at 25 min after tetanus was significantly increased as compared with untreated epileptic mice (left) $(* * P<0.01)$. Antiepileptic treatment was also able to block the short-term potentiation observed in fast-spiking (FS) interneurons of mutants. The right panel shows the amplitude of excitatory postsynaptic potential (EPSPs) measured at 5 min after tetanus (right) $(* * P<0.01)$. (C) Chronic treatment with VPA was also able to reverse the altered NR2A/NR2B NMDA receptor subunit ratio observed in the striata of $B s n$ mutant mice. WB, western blotting; WT, wild type.

Another critical factor that may play a role in the reduction of synaptic plasticity in the MS neurons of Bsn mutant mice is the emergence of a new form of synaptic plasticity in the PV-positive interneurons. Striatal PV-positive FS interneurons receive a critical glutamatergic input from the cortex, and provide the major synaptic inhibitory control within the striatum (Ramanathan et al., 2002). As in 


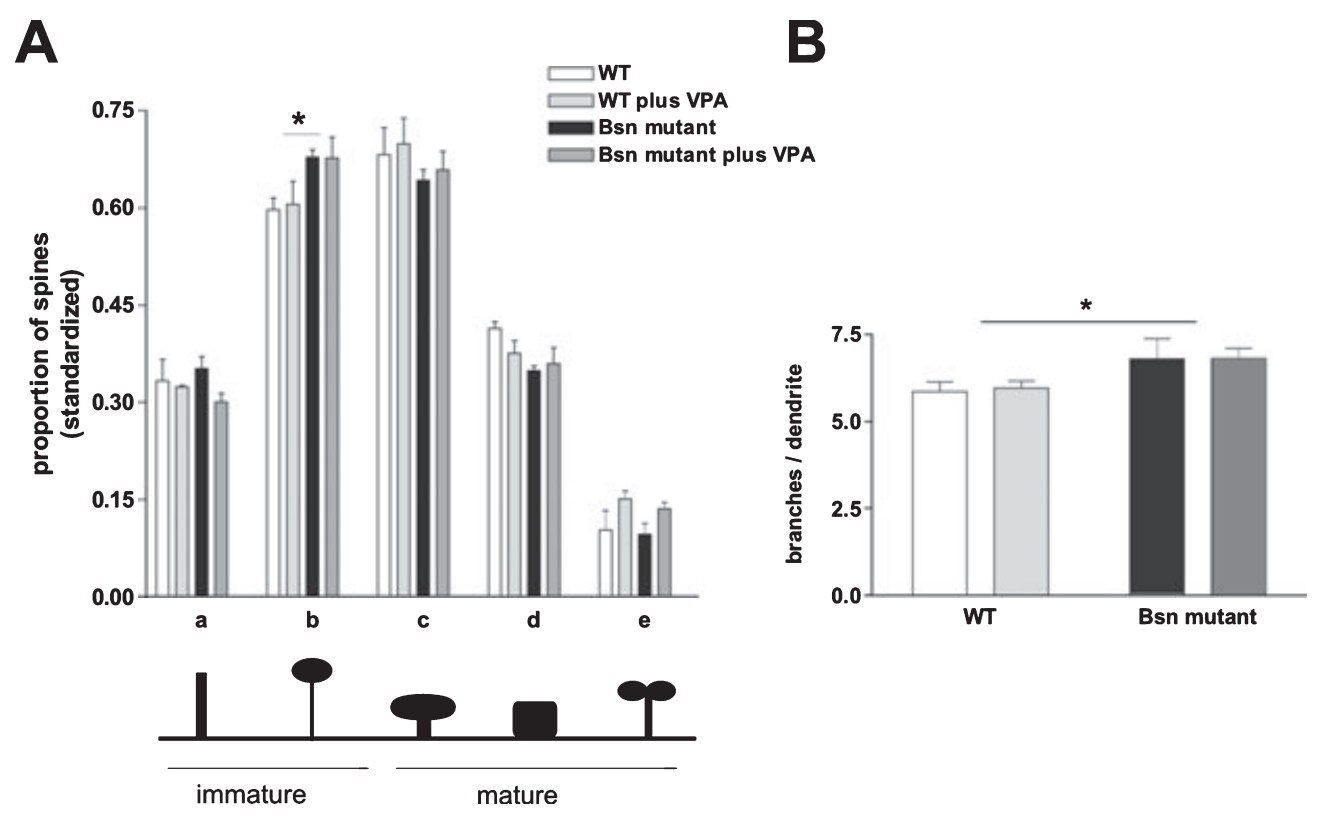

FIG. 7. Chronic valproic acid (VPA) treatment did not prevent increases in branching and spine immaturity of medium spiny (MS) neurons. (A) The histogram shows the distribution of spine morphology types encountered on MS dendrites of treated and untreated Bsn mutant and wild-type (WT) mice. (B) The branching of MS dendrites was also unaffected by the VPA treatment. Treated mice exhibited a morphological pattern that is similar to the one observed in untreated mice. ${ }^{*} P<0.05$.

A

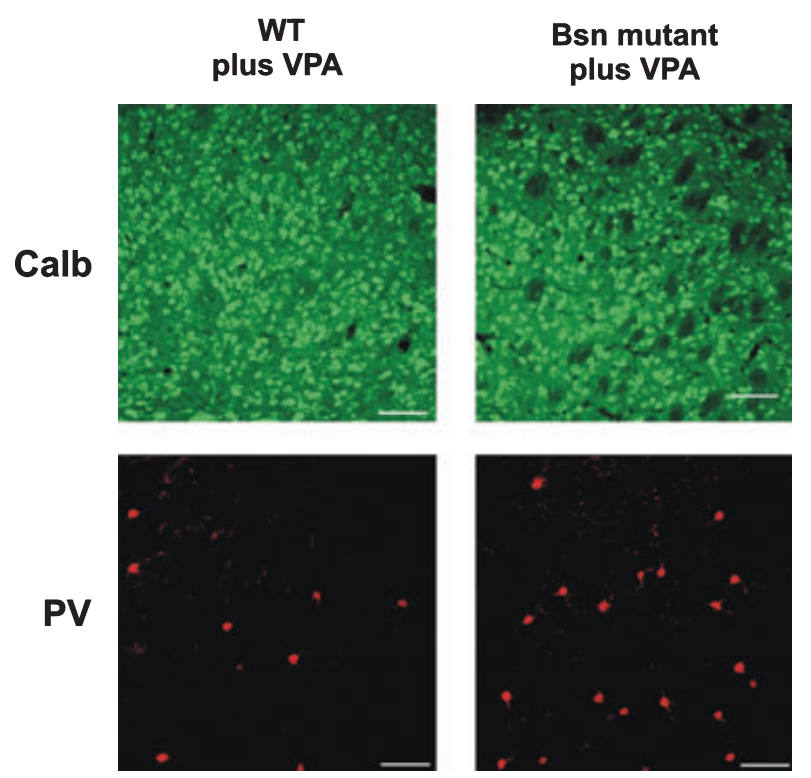

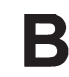
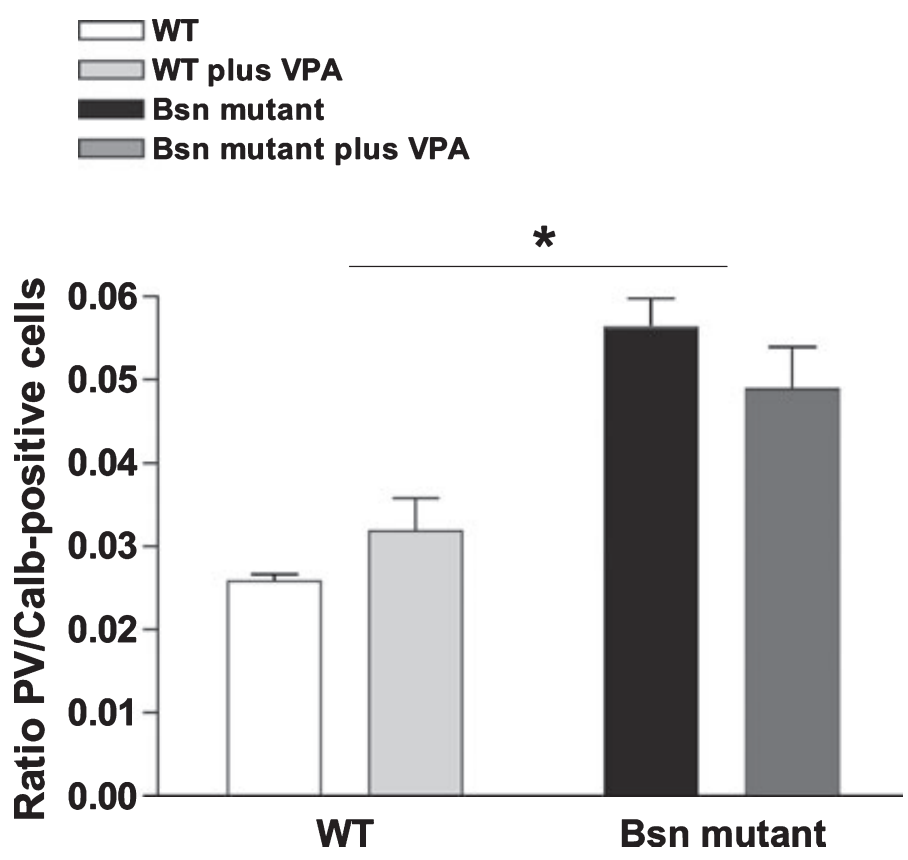

FIG. 8. Chronic valproic acid (VPA) treatment failed to prevent parvalbumin (PV) overexpression in the striatum of treated mutant mice. (A) Examples of calbindin (Calb; upper panels) and PV (lower panels) immunohistochemistry performed in the striatum of Bsn mutant mice (left) and Bsn mutant mice chronically treated with VPA (right). All panels correspond to $\times 20$ magnification. (B) Comparisons of the ratio between striatal calbindin-positive and PV-positive cells in the two genotypes with and without VPA treatment. The histogram shows that the numbers of fast-spiking interneurons and medium spiny neurons were not affected by VPA treatment $(* P<0.05)$. WT, wild type.

MS neurons recorded from animals lacking Bsn, the ability to enhance synaptic strength was altered, FS interneurons showed a form of plasticity that was absent in normal conditions. The importance of PV-positive neurons in epileptic models has already been hypothesized, and, notably, FS interneurons have been implicated in neuronal survival, as a higher susceptibility to seizures is associated with hippocampal PV deficiency (Schwaller et al., 2004) and abnormal firing of cortical FS interneurons (Lau et al., 2000). Moreover, in a genetic model of absence epilepsy, striatal FS interneurons have been reported to modulate MS neuronal activity by changing the firing 
pattern in response to cortical seizures (Slaght et al., 2004). Given this acknowledged role of FS interneurons in epileptic conditions, we tested whether these cells respond to repetitive corticostriatal stimulation, which is known to induce synaptic changes in the MS neuronal subtype. Despite the maintenance of intrinsic properties, FS interneurons of Bsn mutants showed an NMDA-dependent increase in synaptic strength following HFS of corticostriatal synapses, whereas neurons recorded from wild-type mice showed either no change or a small transient synaptic depression.

Besides the expression of this uncommon form of plasticity, we also found a higher number of FS interneurons in Bsn mutant mice. The alteration in MS neuron plasticity was therefore paralleled by an enhancement of FS interneuronal activity, possibly leading to a reorganization of GABAergic control on striatal output activity. However, there is no substantial evidence to support the notion that MS neurons would receive more GABAergic inputs. In fact, we failed to obtain morphological data to demonstrate that PV interneurons increase their connections to MS neurons. In addition, inhibition of GABAergic inputs to MS neurons by bicucullin application (data not shown) was not able to rescue MS LTP. Thus, it is unclear whether enhancement of interneuronal activity makes a contribution to MS plasticity changes. Moreover, overall striatal modifications might not be sufficient, in the end, to preserve the cortex from the recurrence of the seizures, which often lead to death in homozygous mutants.

In order to distinguish between the consequences of Bsn mutation per se and the effects of the seizures, and to clarify the causes of these functional and structural alterations, we explored how the antiepileptic action of VPA could affect corticostriatal modifications in Bsn mutants. Following chronic administration of VPA, mutant mice developed a lower number of epileptic attacks and showed a significant increase in survival rate as compared with untreated Bsn mice. These beneficial effects were accompanied by the recovery of LTP amplitude in MS neurons and a normalization of the levels of NMDA receptor subunits. Conversely, MS neuron morphological alterations were not affected by the treatment. Interestingly, in the other neuronal subtype analysed, the FS interneurons, chronic treatment with VPA also differentially affected functional and morphological features. In fact, although antiepileptic therapy prevented the occurrence of the abnormal short-term potentiation, it did not affect the increase in PV-positive cell numbers in the striatum of epileptic mice. Thus, our experiments show that chronic VPA, through reduction of epileptic seizures, is able to selectively prevent the occurrence of functional alterations in mutant mice without influencing morphological abnormalities, which seem more likely to reflect a direct effect of the abnormal genotype. Interestingly, it has been demonstrated that PV-positive FS interneurons play a critical role in temporal lobe epilepsy by shaping and controlling the power of gamma network oscillations, which are considered to be a neuronal substrate for epileptogenesis (Fisher et al., 1992; Bragin et al., 2007). Although striatal FS GABAergic interneurons are known to have the capacity to fire at very high frequencies and coordinate synchronous activity in large populations of MS neurons (Koos \& Tepper, 1999; Ramanathan et al., 2002), the specific role of interneuronal oscillations has not been clarified in the epileptic striatum.

It is well established that VPA exerts its antiepileptic action via multiple mechanisms, such as sodium channel blockade, antagonism of GABA transaminase, and possible modulation of calcium channels (Rogawski \& Loscher, 2004). Moreover, it has been demonstrated that, in cortical neurons, similar to neurotrophic factors, VPA promotes neurogenesis by enhancing the functions of the extracellular signal-related kinase pathway (Hao et al., 2004), which is dependent on activation of NR2B-containing NMDA receptors (Krapivinsky et al., 2003; Kim et al., 2005) and is critical for corticostriatal LTP (Calabresi et al., 2002). However, the precise mechanism of action by which VPA produces its therapeutic effect in our experimental model has not been investigated, and further experiments are required to clarify this issue. In particular, it would be interesting to explore whether other AEDs targeting sodium channels, such as carbamazepine, would be equally effective in reducing seizures and mortality, as well as in restoring physiological synaptic plasticity and the NR2A/NR2B ratio in Bsn mutant mice.

In conclusion, loss of functional Bassoon leads to the development of a severe epileptic syndrome associated with striatal alterations as an adaptive mechanism within the striatal microcircuit. The presynaptic protein seems to have a key role in the control of neuronal connectivity, which may, in turn, be the initial cause of epileptic symptoms. The early onset of the seizure attacks and their reduction by chronic VPA indicate that changes in corticostriatal synaptic plasticity are likely to be caused by the effects of continuous cortical epileptic activity. These alterations in neuronal activity associated with the occurrence of spontaneous early seizures make this new model of epilepsy a good tool to explore the pathophysiology of basal ganglia in an epileptic syndrome.

Our results indicate that, although it is not possible to prevent the development of morphological conditions that may favor seizure recurrence, an early therapeutic approach, able to limit the seizures, might be able to prevent the occurrence of cell-type-specific alterations in synaptic plasticity induced by recurrent paroxysmal activity.

\section{Supporting Information}

Additional supporting information may be found in the online version of this article:

Fig. S1. Input-output profile of MS neurons and FS interneurons. Video S1. Video-recording of epileptic attack in a Bsn mutant at P14. Video S2. Video-recording of epileptic attack in a Bsn mutant at 2 months.

Please note: Wiley-Blackwell are not responsible for the content or functionality of any supporting materials supplied by the authors. Any queries (other than missing material) should be directed to the corresponding author for the article.

\section{Acknowledgements}

This work was supported by the European Community (LSHM-CT-2004511995, SYNSCAFF; HEALTH-2007-22918, REPLACES) (P. Calabresi, E.D. Gundelfinger, and M. Di Luca), Ricerca Corrente IRCCS (G. Bernardi) and Ricerca Finalizzata IRCCS (P. Calabresi), and the Fonds der Chemischen Industrie, the Alexander von Humboldt Foundation and the Max Planck Society (E. D. Gundelfinger).

\section{Abbreviations}

AED, antiepileptic drug; EPSP, excitatory postsynaptic potential; FS, fastspiking; GABA, $\gamma$-aminobutyric acid; HFS, high-frequency stimulation; LTP, long-term potentiation; MS, medium spiny; NA, numerical aperture; NDS, normal donkey serum; NMDA, $N$-methyl-D-aspartate; P, postnatal day; PB, phosphate buffer; PSD, postsynaptic density; PV, parvalbumin; TBS, Trisbuffered saline; VPA, valproic acid; TIF, Triton-insoluble fraction.

\section{References}

Altrock, W.D., tom Dieck, S., Sokolov, M., Meyer, A.C., Sigler, A., Brakebusch, C., Fassler, R., Richter, K., Boeckers, T.M., Potschka, H., Brandt, C., Loscher, W., Grimberg, D., Dresbach, T., Hempelmann, A., 
Hassan, H., Balschun, D., Frey, J.U., Brandstatter, J.H., Garner, C.C., Rosenmund, C. \& Gundelfinger, E.D. (2003) Functional inactivation of a fraction of excitatory synapses in mice deficient for the active zone protein bassoon. Neuron, 37, 787-800.

Bartlett, T.E., Bannister, N.J., Collett, V.J., Dargan, S.L., Massey, P.V., Bortolotto, Z.A., Fitzjohn, S.M., Bashir, Z.I., Collingridge, G.L. \& Lodge, D. (2007) Differential roles of NR2A and NR2B-containing NMDA receptors in LTP and LTD in the CA1 region of two-week old rat hippocampus. Neuropharmacology, 52, 60-70.

Bortolotto, Z.A. \& Collingridge, G.L. (1998) Involvement of calcium/ calmodulin-dependent protein kinases in the setting of a molecular switch involved in hippocampal LTP. Neuropharmacology, 37, 535-544.

Bouilleret, V., Semah, F., Chassoux, F., Mantzaridez, M., Biraben, A., Trebossen, R. \& Ribeiro, M.J. (2008) Basal ganglia involvement in temporal lobe epilepsy: a functional and morphologic study. Neurology, 70, 177-184.

Bracci, E., Centonze, D., Bernardi, G. \& Calabresi, P. (2002) Dopamine excites fast-spiking interneurons in the striatum. J. Neurophysiol., 87, 2190-2194.

Bracci, E., Centonze, D., Bernardi, G. \& Calabresi, P. (2004) Engagement of rat striatal neurons by cortical epileptiform activity investigated with paired recordings. J. Neurophysiol., 92, 2725-2737.

Bragin, A., Claeys, P., Vonck, K., Van Roost, D., Wilson, C., Boon, P. \& Engel, J. Jr (2007) Analysis of initial slow waves (ISWs) at the seizure onset in patients with drug resistant temporal lobe epilepsy. Epilepsia, 48, 18831894.

Calabresi, P., Pisani, A., Mercuri, N.B. \& Bernardi, G. (1992) Long-term potentiation in the striatum is unmasked by removing the voltage-dependent magnesium block of NMDA receptor channels. Eur. J. Neurosci., 4, 929935 .

Calabresi, P., Gubellini, P., Centonze, D., Picconi, B., Bernardi, G., Chergui, K., Svenningsson, P., Fienberg, A.A. \& Greengard, P. (2000) Dopamine and cAMP-regulated phosphoprotein $32 \mathrm{kDa}$ controls both striatal long-term depression and long-term potentiation, opposing forms of synaptic plasticity. J. Neurosci., 20, 8443-8451.

Calabresi, P., Saulle, E., Centonze, D., Pisani, A., Marfia, G.A. \& Bernardi, G. (2002) Post-ischaemic long-term synaptic potentiation in the striatum: a putative mechanism for cell type-specific vulnerability. Brain, 125, 844-860.

Calabresi, P., Picconi, B., Tozzi, A. \& Di Filippo, M. (2007) Dopaminemediated regulation of corticostriatal synaptic plasticity. Trends Neurosci., 30, 211-219.

Chapman, A.G., De Sarro, G.B., Premachandra, M. \& Meldrum, B.S. (1987) Bidirectional effects of beta-carbolines in reflex epilepsy. Brain Res. Bull., 19, 337-346.

Coggeshall, R.E. (1992) A consideration of neural counting methods. Trends Neurosci., 15, 9-13.

De Sarro, G., Russo, E., Ferreri, G., Giuseppe, B., Flocco, M.A., Di Paola, E.D. \& De Sarro, A. (2004) Seizure susceptibility to various convulsant stimuli of knockout interleukin-6 mice. Pharmacol. Biochem. Behav., 77, 761-766.

tom Dieck, S., Sanmarti-Vila, L., Langnaese, K., Richter, K., Kindler, S., Soyke, A., Wex, H., Smalla, K.H., Kampf, U., Franzer, J.T., Stumm, M., Garner, C.C. \& Gundelfinger, E.D. (1998) Bassoon, a novel zinc-finger $\mathrm{CAG} /$ glutamine-repeat protein selectively localized at the active zone of presynaptic nerve terminals. J. Cell Biol., 142, 499-509.

Engstrom, F.L. \& Woodbury, D.M. (1988) Seizure susceptibility in DBA and C57 mice: the effects of various convulsants. Epilepsia, 29, 389-395.

Fiala, J.C., Spacek, J. \& Harris, K.M. (2002) Dendritic spine pathology: cause or consequence of neurological disorders? Brain Res. Brain Res. Rev., 39, 29-54.

Finardi, A., Gardoni, F., Bassanini, S., Lasio, G., Cossu, M., Tassi, L., Caccia, C., Taroni, F., LoRusso, G., Di Luca, M. \& Battaglia, G. (2006) NMDA receptor composition differs among anatomically diverse malformations of cortical development. J. Neuropathol. Exp. Neurol., 65, 883893.

Fisher, R.S., Webber, W.R., Lesser, R.P., Arroyo, S. \& Uematsu, S. (1992) High-frequency EEG activity at the start of seizures. J. Clin. Neurophysiol., 9, 441-448.

Gardoni, F., Schrama, L.H., Kamal, A., Gispen, W.H., Cattabeni, F. \& Di Luca, M. (2001) Hippocampal synaptic plasticity involves competition between $\mathrm{Ca}^{2+} /$ calmodulin-dependent protein kinase II and postsynaptic density 95 for binding to the NR2A subunit of the NMDA receptor. J. Neurosci., 21, 1501-1509.

Gardoni, F., Picconi, B., Ghiglieri, V., Polli, F., Bagetta, V., Bernardi, G., Cattabeni, F., Di Luca, M. \& Calabresi, P. (2006) A critical interaction between NR2B and MAGUK in L-DOPA induced dyskinesia. J. Neurosci., 26, 2914-2922.
Gardoni, F., Mauceri, D., Malinverno, M., Polli, F., Costa, C., Tozzi, A., Siliquini, S., Picconi, B., Cattabeni, F., Calabresi, P. \& Di Luca, M. (2009) Decreased NR2B subunit synaptic levels cause impaired long-term potentiation but not long-term depression. J. Neurosci., 29, 669-677.

Garner, C.C., Kindler, S. \& Gundelfinger, E.D. (2000) Molecular determinants of presynaptic active zones. Curr. Opin. Neurobiol., 10, 321-327.

Gibb, R. \& Kolb, B. (1998) A method for vibratome sectioning of Golgi-Cox stained whole rat brain. J. Neurosci. Methods, 79, 1-4.

Glaser, E.M. \& Van der Loos, H. (1981) Analysis of thick brain sections by obverse-reverse computer microscopy: application of a new, high clarity Golgi-Nissl stain. J. Neurosci. Methods, 4, 117-125.

Hao, Y., Creson, T., Zhang, L., Li, P., Du, F., Yuan, P., Gould, T.D., Manji, H.K. \& Chen, G. (2004) Mood stabilizer valproate promotes ERK pathwaydependent cortical neuronal growth and neurogenesis. J. Neurosci., 24, 6590-6599.

Horner, C.H. \& Arbuthnott, E. (1991) Methods of estimation of spine density are spines evenly distributed throughout the dendritic field? J. Anat., 177, 179-184.

Irwin, S.A., Patel, B., Idupulapati, M., Harris, J.B., Crisostomo, R.A., Larsen, B.P., Kooy, F., Willems, P.J., Cras, P., Kozlowski, P.B., Swain, R.A., Weiler, I.J. \& Greenough, W.T. (2001) Abnormal dendritic spine characteristics in the temporal and visual cortices of patients with fragile-X syndrome: a quantitative examination. Am. J. Med. Genet., 98, 161-167.

Kawaguchi, Y. (1993) Physiological, morphological, and histochemical characterization of three classes of interneurons in rat neostriatum. J. Neurosci., 13, 4908-4923.

Kawaguchi, Y., Wilson, C.J., Augood, S.J. \& Emson, P.C. (1995) Striatal interneurones: chemical, physiological and morphological characterization. Trends Neurosci., 18, 527-535.

Kim, E. \& Sheng, M. (2004) PDZ domain proteins of synapses. Nat. Rev Neurosci., 5, 771-781.

Kim, M.J., Dunah, A.W., Wang, Y.T. \& Sheng, M. (2005) Differential roles of NR2A- and NR2B-containing NMDA receptors in Ras-ERK signaling and AMPA receptor trafficking. Neuron, 46, 745-760.

Koos, T. \& Tepper, J.M. (1999) Inhibitory control of neostriatal projection neurons by GABAergic interneurons. Nat. Neurosci., 2, 467-472.

Krapivinsky, G., Krapivinsky, L., Manasian, Y., Ivanov, A., Tyzio, R., Pellegrino, C., Ben-Ari, Y., Clapham, D.E. \& Medina, I. (2003) The NMDA receptor is coupled to the ERK pathway by a direct interaction between NR2B and RasGRF1. Neuron, 40, 775-784.

Lau, D., Vega-Saenz de Miera, E.C., Contreras, D., Ozaita, A., Harvey, M., Chow, A., Noebels, J.L., Paylor, R., Morgan, J.I., Leonard, C.S. \& Rudy, B. (2000) Impaired fast-spiking, suppressed cortical inhibition, and increased susceptibility to seizures in mice lacking $\mathrm{Kv} 3.2 \mathrm{~K}+$ channel proteins. J. Neurosci., 20, 9071-9085.

Leuner, B., Falduto, J. \& Shors, T.J. (2003) Associative memory formation increases the observation of dendritic spines in the hippocampus. J. Neurosci., 23, 659-665.

Mallet, N., Le Moine, C., Charpier, S. \& Gonon, F. (2005) Feedforward inhibition of projection neurons by fast-spiking GABA interneurons in the rat striatum in vivo. J. Neurosci., 25, 3857-3869.

Musumeci, S.A., Bosco, P., Calabrese, G., Bakker, C., De Sarro, G.B., Elia, M., Ferri, R. \& Oostra, B.A. (2000) Audiogenic seizures susceptibility in transgenic mice with fragile X syndrome. Epilepsia, 41, 19-23.

Picconi, B., Gardoni, F., Centonze, D., Mauceri, D., Cenci, M.A., Bernardi, G., Calabresi, P. \& Di Luca, M. (2004) Abnormal Ca2+-calmodulin-dependent protein kinase II function mediates synaptic and motor deficits in experimental parkinsonism. J. Neurosci., 24, 5283-5291.

Ramanathan, S., Hanley, J.J., Deniau, J.M. \& Bolam, J.P. (2002) Synaptic convergence of motor and somatosensory cortical afferents onto GABAergic interneurons in the rat striatum. J. Neurosci., 22, 8158-8169.

Richter, K., Langnaese, K., Kreutz, M.R., Olias, G., Zhai, R., Scheich, H., Garner, C.C. \& Gundelfinger, E.D. (1999) Presynaptic cytomatrix protein bassoon is localized at both excitatory and inhibitory synapses of rat brain. J. Comp. Neurol., 408, 437-448.

Rogawski, M.A. \& Loscher, W. (2004) The neurobiology of antiepileptic drugs. Nat. Rev. Neurosci., 5, 553-564.

Schmitz, C. \& Hof, P.R. (2005) Design-based stereology in neuroscience. Neuroscience, 130, 813-831.

Schoch, S. \& Gundelfinger, E.D. (2006) Molecular organization of the presynaptic active zone. Cell Tissue Res., 326, 379-391.

Schwaller, B., Tetko, I.V., Tandon, P., Silveira, D.C., Vreugdenhil, M., Henzi, T., Potier, M.C., Celio, M.R. \& Villa, A.E. (2004) Parvalbumin deficiency affects network properties resulting in increased susceptibility to epileptic seizures. Mol. Cell. Neurosci., 25, 650-663. 
Slaght, S.J., Paz, T., Mahon, S., Maurice, N., Charpier, S. \& Deniau, J.M. (2002) Functional organization of the circuits connecting the cerebral cortex and the basal ganglia: implications for the role of the basal ganglia in epilepsy. Epileptic Disord, 4(Suppl. 3), S9-S22.

Slaght, S.J., Paz, T., Chavez, M., Deniau, J.M., Mahon, S. \& Charpier, S. (2004) On the activity of the corticostriatal networks during spike-and-wave discharges in a genetic model of absence epilepsy. J. Neurosci., 24, 68166825 .

Sterio, D.C. (1984) The unbiased estimation of number and sizes of arbitrary particles using the disector. J. Microsc., 134, 127-136.

Tada, T. \& Sheng, M. (2006) Molecular mechanisms of dendritic spine morphogenesis. Curr. Opin. Neurobiol., 16, 95-101.

Tepper, J.M., Koos, T. \& Wilson, C.J. (2004) GABAergic microcircuits in the neostriatum. Trends Neurosci., 27, 662-669.

Uylings, H.B., Ruiz-Marcos, A. \& van Pelt, J. (1986) The metric analysis of three-dimensional dendritic tree patterns: a methodological review. J. Neurosci. Methods, 18, 127-151.
Winter, C., tom Dieck, S., Boeckers, T.M., Bockmann, J., Kampf, U., Sanmarti-Vila, L., Langnaese, K., Altrock, W., Stumm, M., Soyke, A., Wieacker, P., Garner, C.C. \& Gundelfinger, E.D. (1999) The presynaptic cytomatrix protein Bassoon: sequence and chromosomal localization of the human BSN gene. Genomics, 57, 389-397.

Wyneken, U., Smalla, K.H., Marengo, J.J., Soto, D., de la Cerda, A., Tischmeyer, W., Grimm, R., Boeckers, T.M., Wolf, G., Orrego, F. \& Gundelfinger, E.D. (2001) Kainate-induced seizures alter protein composition and $N$-methyl-D-aspartate receptor function of rat forebrain postsynaptic densities. Neuroscience, 102, 65-74.

Wyneken, U., Marengo, J.J., Villanueva, S., Soto, D., Sandoval, R. Gundelfinger, E.D. \& Orrego, F. (2003) Epilepsy-induced changes in signaling systems of human and rat postsynaptic densities. Epilepsia, 44, 243-246.

Yashiro, K. \& Philpot, B.D. (2008) Regulation of NMDA receptor subunit expression and its implications for LTD, LTP, and metaplasticity. Neuropharmacology, 55, 1081-1094. 